\title{
Socioeconomic and Health Determinants of Health Care Utilization Among ELDERLY EUROPEANS: A SEMIPARAMETRIC ASSESSMENT OF EQUITY, INTENSITY AND RESPONSIVENESS FOR TEN EUROPEAN COUNTRIES
}

Jürgen Maurer 


\title{
Socioeconomic and Health Determinants of Health Care Utilization Among Elderly Europeans: A Semiparametric Assessment of Equity, Intensity and Responsiveness for Ten European Countries
}

\author{
Jürgen Maurer* \\ This Version: October 2006 (First Version: April 2006)
}

\begin{abstract}
This paper investigates the interplay of socioeconomic and medical determinants of health care utilization among elderly Europeans from ten countries. Using novel strictly comparable cross-national data from the Survey of Health, Ageing and Retirement in Europe (SHARE), the study exploits recent semi- and nonparametric estimation methods to illustrate how individual socioeconomic status and health determine health care utilization in different institutional settings. Our flexible estimation method allows for the use of multiple health measures to adjust for individual differences in health care need without sacrificing cross-national comparability of the resulting estimates. Within countries, we find only a small, if any, socioeconomic gradient. Moreover, all health systems appear to be reasonably responsive to differences in care need. At the same time, we find considerable variation in treatment intensity across countries, which we cannot fully explain by differences in health care need.
\end{abstract}

Keywords: Health Care Utilization, Equity, International Comparison, Semiparametric Methods

*Mannheim Research Institute for the Economics of Aging (MEA), University of Mannheim, L13, 17, 68131 Mannheim, Germany. Email: juergen.maurer@iue.it. I would like to thank Roger Klein and Frank Vella for sharing some of their GAUSS routines with me. I would also like to thank seminar participants at the University of Mannheim as well as participants of the 15th European Workshop on Econometrics and Health Economics in Thessaloniki, especially my discussant - Eddy van Doorslaer - for very helpful comments and suggestions. Of course, all remaining errors are my own responsibility. 


\section{Introduction}

Health and socioeconomic status are strongly related. ${ }^{1}$ There is ample evidence for pervasive socioeconomic gradients in health within and across countries as well as over time, highlighting social inequalities in health as a nearly universal feature of society. Individuals with low socioeconomic status generally have worse health outcomes than more advantaged members of society, exacerbating any preexisting socioeconomic gradients in wellbeing. The reflection of deprivation and privilege in populations patterns of health has therefore led to considerable concern amongst policy-makers.

The current paper investigates the accessibility and responsiveness of European health care systems for elderly individuals with different socioeconomic and health status. Ensuring socioeconomic equity and responsiveness of the health care system is often considered a high priority in health policy making, as lack of access and responsiveness may cause or at least reinforce socioeconomic gradients is health. It is therefore widely believed that health care should be delivered according to "equal treatment for equal need" and appropriately reflect differences in health care need across individuals. ${ }^{2}$

Our study uses novel data from the first wave of the Survey of Health, Ageing and Retirement in Europe (SHARE) collected in 2004. SHARE is a unique interdisciplinary cross-national data source on health, economic position and quality of life of elderly Europeans ten countries. Due to identical questionnaire design and data collection procedures in all participating countries, SHARE represents an ideal data source for a comparative analysis of horizontal equity and responsiveness of different health care systems. In fact, the data appear tailor-made for comparing patterns of health care utilization across countries, as their extensive information on individual background health allows us to control well for any possible cross-country differences in health care need. Specifically, we can compare care utilization patterns of individuals with similar health care need who face different institutional arrangements as implied by their respective country's health care system.

Overall, the paper aims at providing a flexible descriptive analysis of the determinants of health care utilization of elderly Europeans. We characterize individual health care utilization as a function of socioeconomic status and health care need. Rather than trying to build full-blown structural models for individual health care utilization in each of the ten different health care systems, we follow an approach suggested in Deaton (1997) and "present features of the data (...) through graphical presentations of densities and regression functions, and then (...) think about whether these features tell us anything useful about the process whereby they were generated" (Deaton (1997), p.4). Our corresponding econometric analysis uses concepts from the more recent literature on semi- and nonparametric econometrics to "let the data speak" with maximal generality. At the same time, we show how to enhance comparability and efficiency in the estimations using mild cross-country restrictions that appear to come at a rather low cost in terms of model flexibility.

The reminder of the paper is organized as follows: Section 2 provides some additional background and motivation while section 3 presents our econometric framework. Section 4 gives a brief account of the data and explains how we specify our empirical model. Section 5 discusses some of the key results. Section 6 concludes with some final remarks.

\footnotetext{
${ }^{1}$ A survey of this very extensive literature is far beyond the scope of this paper. Adler and Newman (2002), Adler et al. (2000), Deaton (2003), Marmot (2005), Marmot and Wilkinson (1999) and Smith (1999, 2003, 2004) represent excellent introductions to key aspects of the subject.

${ }^{2}$ See for example van Doorslaer et al. (1993, 2000), Wagstaff and van Doorslaer (2000) or OECD (2004) for further discussion of these policy objectives and additional references.
} 


\section{Background and Motivation}

The present study is by no means the first attempt to the relationship between socioeconomic status, background health and health care utilization in a comparative setting. ${ }^{3}$ While there seems to be no univocal agreement, most previous research on horizontal (in-)equity in health care utilization in Europe detects a pro-poor gradient in health care utilization for most countries. However, these gradients oftentimes vanish or even reverse after incorporating some health care need adjustment. Hence, while overall health care utilization appears to be pro-poor on balance, "need-adjusted" care utilization generally displays the reverse pattern. These findings further highlight that "need-adjustments" play a crucial role in the assessment of equity in health care utilization. Yet, due to a lack of rich comparable health data, most previous studies of socioeconomic inequality in health care utilization use simple subjective self-assessments of individual health and functioning. ${ }^{4}$ Apart from providing only a fairly incomplete picture of individual background health, such an approach may be criticized on the grounds that purely subjective health assessments may have little objective content, lack crossnational comparability, and be very vulnerable to justification biases for respondents reporting heavy use of health care. ${ }^{5}$

The present paper contains several novelties regarding both methodology and underlying data. Firstly, we suggest a semiparametric modelling framework which allows for a straightforward assessment of horizontal equity, vertical equity (responsiveness) and utilization intensity, even in the presence of a large number of health controls capturing differences in individual health care need. We proceed with a nonparametric characterization of key aspects of the conditional distribution of health care utilization given both socioeconomic status and a comprehensive health care need index to account for differences in background health. An important aim of the paper is to unravel the interplay between socioeconomic status, health and their interactions in determining health care utilization, highlighting similarities and differences featured by different health care systems across Europe. Our study thus complements more aggregate approaches by analyzing the full conditional distribution of health care utilization given socioeconomic status and background health. Rather than reverting to some unidimensional summary statistic, we describe the entire distribution of health, socioeconomic status, and health care utilization from which any such statistic could be computed if desired. We illustrate this point by also computing partial means to assess horizontal equity, vertical equity as well as cross-country heterogeneity in utilization intensity. Yet, relative to previous parametric approaches, the momentary lack of standardized inference procedures ought to be noted as a downside of our method.

Apart from these methodological innovations, our study has the additional advantage that it is based on the novel SHARE survey which is closely comparable data from one source. Most previous comparative studies relied on numerous national data sources, whose differing design and content may complicate a sound comparison. ${ }^{6}$ In addition, SHARE contains numerous objective and quasi-

\footnotetext{
${ }^{3}$ See e.g. van Doorslaer et al. (1993, 2000) or Wagstaff and van Doorslaer (2000) for a more comprehensive discussion and literature overview.

${ }^{4}$ Typically used proxies for perceived differences in health care need include self-reported general health on a five category scale and/or dummy variables indicating the presence of any mobility limitation or disability.

${ }^{5}$ See e. g. Groot (2000), Sen (2002), Lindeboom and van Doorslaer (2004), Jürges (2006).

${ }^{6}$ A notable exception is van Doorslaer et al. (2004) who use comparable data from the European Community Household Panel (ECHP). However, the ECHP only contains very limited information on individual background health, rendering appropriate health care need adjustments a rather delicate exercise.
} 
objective assessments of individual health which greatly enhance the reliability and comparability of the health care need adjustment across different cultural and institutional settings. At the same time, the SHARE data have not yet been used to investigate international and socioeconomic differences in need-adjusted health care utilization as well as issues of responsiveness and treatment intensity of different European health care systems.

\section{$3 \quad$ Econometric Strategy}

Our econometric strategy strikes a balance between estimating a full count data model for overall health care utilization $Y_{i}$ and a rather crude regression approach estimating conditional expectations functions only.

Consider two known consecutive, nonnegative and discrete cutoffs $c_{j}$ and $c_{k}$ from a set of given cut-off point $C$ with $c_{j}<c_{k}$. We then analyze conditional probabilities of events of the form $\left\{c_{j}<Y_{i} \leq c_{k}\right\}$, i.e.

$$
P_{C_{i} G_{i}}\left(c_{j}<Y_{i} \leq c_{k} \mid S_{i}, H_{i} \beta_{G_{i}}\right)
$$

which can be equivalently written as

$$
P_{C_{i} G_{i}}\left(c_{j}<Y_{i} \leq c_{k} \mid S_{i}, H_{i} \beta_{G_{i}}\right)=P_{C_{i} G_{i}}\left(Y_{i}>c_{j} \mid S_{i}, H_{i} \beta_{G_{i}}\right)-P_{C_{i} G_{i}}\left(Y_{i}>c_{k} \mid S_{i}, H_{i} \beta_{G_{i}}\right)
$$

where $S_{i}$ denotes individual $i$ 's socioeconomic status and $H_{i} \beta_{G_{i}}$ represents her health care need as summarized by a one-dimensional background health index. $P_{C_{i} G_{i}}\left(I \mid S_{i}, H_{i} \beta_{G_{i}}\right)$ represents a countryand gender-specific nonparametric link function mapping individual $i$ 's socioeconomic status and background health into the conditional probability of event $I$. In the estimations, the coefficient $\beta_{G_{i}}$ are assumed to be gender-specific but identical across countries. ${ }^{7}$

The indices $H_{i} \beta_{G_{i}}$ thus approximate individual health care need irrespective of the institutional arrangements of any particular health care system under consideration with the latter being entirely incorporated in the nonparametric country- and gender-specific probability functions $P_{C_{i} G_{i}}\left(I \mid S_{i}, H_{i} \beta_{G_{i}}\right)$. Specifically, for any given pair $\left(S_{i}, H_{i} \beta_{G_{i}}\right)$, these probabilities are estimated by separately applying bivariate kernel smoothers within each possible gender-country-strata. Thus, our estimations thus allow for fully country- and gender-specific health care utilization patterns, as both location and scale of the effects of $S_{i}$ and $H_{i} \beta_{G_{i}}$ on $I$ are factored in $P_{C_{i} G_{i}}\left(I \mid S_{i}, H_{i} \beta_{G_{i}}\right)$. Given that the health indices are therefore only identified up to location and scale and we set the coefficients of age equal to one for normalization purposes. ${ }^{8} H_{i} \beta_{G_{i}}$ thus measures health care need in gender-specific age units, thus capturing basic biological and medical trade-offs between age and various health conditions, symptoms and other morbidity measures. The index coefficients $\beta_{G_{i}}$, in turn, are obtained from a gender-specific semiparametric likelihood function that pools the data for all countries, yet incorporating the flexible country-specific nonparametric link between socioeconomic status $S_{i}$ and health care need $H_{i} \beta_{G_{i}}$ on

\footnotetext{
${ }^{7}$ Note that this assumption is by no means necessary. Yet, it seems rather mild given our set of nonparametric country- and gender-specific link functions and substantially simplifies any cross-national comparisons regarding treatment intensity. These can now be based on comparing the utilization patterns of individuals with identical index values rather than identical combinations of different health conditions, which would be too numerous to study comprehensively in a paper of limited length.

${ }^{8}$ See e.g. Horowitz (1998) for a more detailed discussion of identification in semiparametric index models.
} 
the one hand, and health care utilization $Y_{i}$ on the other, which also allows for potentially complex interaction effects between $S_{i}$ and $H_{i} \beta_{G_{i}}$.

Given (2), the conditional probabilities of events of the form $\left\{c_{j}<Y_{i} \leq c_{k}\right\}$ can be straightforwardly analyzed by estimating the probabilities of two binary events of the form $\left\{Y_{i}>c_{l}\right\}$. Specifically, for an ordered sequence of cut-off points $c_{j} \in C, j=0, \ldots, K$, the quasi-likelihood for a corresponding ordered response model can be constructed as

$$
L=\prod_{i=1}^{N}\left[\sum_{j=1}^{K} I\left\{c_{j-1}<Y_{i} \leq c_{j}\right\} \cdot\left(P_{C_{i} G_{i}}\left(Y_{i}>c_{j-1} \mid S_{i}, H_{i} \beta_{G_{i}}\right)-P_{C_{i} G_{i}}\left(Y_{i}>c_{j} \mid S_{i}, H_{i} \beta_{G_{i}}\right)\right)\right]
$$

We apply the approach of Klein and Spady (1993) to construct a semiparametric quasi-likelihood which we maximize to estimate the index parameters $\beta_{G_{i}}{ }^{9}$ Given these estimates, we can present bivariate probability plots for different degrees of health care utilization to see how these vary by socioeconomic status and health care need. In addition, we can also compute partial mean estimates to assess the overall degrees of equity and responsiveness for each country's health care system. Specifically, we compute partial means for selected values of socioeconomic status (health care need), integrating out any potentially confounding effect of health care need (socioeconomic status) by replacing its conditional distribution with its corresponding marginal. These aim at separating out "average structural effects" from merely correlated effects that stem from any potential dependence of the two arguments on the right-hand side. ${ }^{10}$ Further details on the estimation procedure as well as computation of the partial mean estimates can be found in the appendix.

\section{Data and Model Specification}

We use data from the first wave of the Survey of Health, Ageing and Retirement in Europe (SHARE) collected in 2004. ${ }^{11}$ SHARE is a multidisciplinary, cross-national micro data base containing information on health and socioeconomic status of some 22,000 Continental Europeans aged 50+. Consistent sampling frames and survey design across all participating countries result in a high degree of crossnational comparability of the SHARE data which is key for best-practice comparative research. We use the data from ten European countries - Austria, Denmark, France, Germany, Greece, Italy, the Netherlands, Spain, Sweden and Switzerland.

To study both medical and socioeconomic determinants of health care utilization, we require a comprehensive, yet comparable set of health indicators capturing health care need as well as a compa-

\footnotetext{
${ }^{9}$ See also Klein and Sherman (2002) for an application of such an estimator to an ordered response model and Klein and Vella (2004) or Maurer, Klein and Vella (2006) for estimation of functions with more than one argument.

${ }^{10}$ Similar partial mean estimates are now commonly used to summarize "structural effects" in nonspeparable semiand nonparametric models featuring endogeneity. See e.g. Blundell and Powell $(2001,2004)$ for a more comprehensive discussion as well as Chamberlain (1984) for a similar idea in a correlated random effects probit framework).

${ }^{11}$ This paper uses data from the early release 1 of SHARE 2004 . This release is preliminary and may contain errors that will be corrected in later releases. The SHARE data collection has been primarily funded by the European Commission through the 5th framework programme (project QLK6-CT-2001-00360 in the thematic programme Quality of Life). Additional funding came from the US National Institute on Ageing (U01 AG09740-13S2, P01 AG005842, P01 AG08291, P30 AG12815, Y1-AG-4553-01 and OGHA 04-064). Data collection in Austria (through the Austrian Science Foundation, FWF), Belgium (through the Belgian Science Policy Office) and Switzerland (through BBW/OFES/UFES) was nationally funded. The SHARE data set is introduced in Börsch-Supan et al. (2005); methodological details are contained in Börsch-Supan and Jürges (2005).
} 
rable marker of socioeconomic status. Regarding the former, SHARE contains numerous indicators for individual health status that can be used to control for individual health differences. Specifically, we use age (and its square), maximum grip strength (and its square) and a large set of dummy variables indicating specific anthropometric features, doctor-diagnosed physical health conditions, symptoms, mental health conditions, cognitive functioning as well as mobility, ADL and IADL limitations. Overall, our health care need index consists of 45 different variables. With such a large set of objective and quasi-objective health indicators at hand, we obtain a fairly comprehensive picture of each respondents health status.

Finding an appropriate marker for socioeconomic status - on the other hand - seems a much more delicate task, especially when considering an elderly population. Firstly, income - the most commonly used socioeconomic status measure in health economics - might represent a rather poor marker in a population in which only a fraction of the respondents work and earn any labor income. A comparison of total current income might thus be largely misleading, implicitly comparing individuals at different stages of their life-cycle earnings profiles. Current income may thus constitute a poor proxy of permanent income. Consumption, on the other hand, is directly linked with the latter and would therefore represent a more sound indicator of SES. However, consumption is notoriously difficult to measure in social surveys, particularly if prompted by a one-shot question as in SHARE. Wealth, in turn, suffers from the same shortcoming as income regarding a potential comparison of individuals at different points of their life-cycle, apart from the general difficulty to obtain reliable wealth information in a survey setting. Given these trade-offs, we choose years of education as our central measure of socioeconomic status. Doing so has several practical advantages over the other aforementioned approaches: Firstly, education is relatively easy to elicit in a survey setting. At the same time, it is well-known to be highly correlated with both financial and nonfinancial measures of socioeconomic status. Education is highly correlated with (lifetime) income, wealth and consumption, but also strongly predicts occupation or social class, two other prominent status measures that are often used in sociology or social epidemiology. Finally, education embodies human capital, too, which might in itself be an important determinant of health care utilization. ${ }^{12}$ While education does in principle also allow for direct cross-country comparisons, we do not focus on such comparisons, as international differences in educational attainment appear to also reflect historical differences in education systems across countries. We thus interpret education as a SES marker within each country - leaving a judgement regarding the plausibility of any cross-country comparisons to the reader.

Finally, we need to take a stance on which aspects of the joint distribution of socioeconomic status, health and health care utilization we would like to focus on as well as how we measure the latter. We use the total number of doctor visits $Y_{i}$ during the last twelve months as our health care utilization measure, which we aggregate into prespecified ordered categories to comprehensively capture various levels of utilization intensity. Specifically, we use the cut-off points of Santos-Eggimann et al. (2005) to define four ordered events, namely "no doctor visit", "1-3 doctor visits", "4-6 doctor visits" and "more than 6 doctor visits". These categories appear to cover key aspects of the overall distribution

\footnotetext{
${ }^{12}$ In fact, other researchers have found that the socioeconomic gradient in health appears largely driven by education - more than by income or wealth with the suggested pathways mainly working through interactions with the typical work environment as well as better health behaviors and patient self-management (see for example Case and Deaton (2005), Goldman and Smith (2002), Smith (2003, 2004) or Cutler and Lleras-Muney (2006) among many others). Thus, an explicit consideration of human capital might be important to also capture the latter effects of self-management as well as any differences in the extent to which patients are able to "surf the system".
} 
of the number of doctor visits, from "no health care use" (i.e. $Y_{i}=0$ ) to comparatively "heavy use" of health care $\left(Y_{i}>6\right) \cdot{ }^{13}$

Table 1 present some sample size information by country and gender. As can be seen from the table, there is a good deal of heterogeneity in sample size across countries, with the number of observations ranging from a low of 414 (men in Switzerland) to 1397 (women in Sweden). While the individual samples seem large enough to allow for two-dimensional nonparametric estimation of health care utilization intensity, it is appears that the sample size are somewhat small for a full country-specific analysis in the presence of a large dimensional set of health care need controls, some of which representing comparatively rare events such as Parkinson's disease or underweight. Hence, considerations of limited sample size and rare events provide an additional motivation for our previously described modelling strategy using pooled data from all countries to estimate the health index $H_{i} \beta_{G_{i}}$. The two health index parameters for men and women are thus estimated using data on 8988 male and 10311 female respondents respectively.

Table 2, in turn, presents some descriptive statistics for our key outcome variable, the total number of doctor visits during the last twelve month. At a first glimpse, there appears to be quite substantial cross-country heterogeneity in the use of health care, with Italy and Spain featuring comparatively high, and Sweden comparatively low levels of utilization.

\section{Results}

Tables 3 and 4 present the parameter estimates of the health care need indices from the ordered response models for men and women respectively. Although some of the corresponding index parameters are not estimated with very high precision, a remarkably consistent picture emerges: Almost all of the included health conditions have a positive sign, which is what we would have expected given our age normalization. ${ }^{14}$ Higher values of $H_{i} \beta_{G_{i}}$ thus correspond to higher values of health care need. Interestingly though, some of our measures of reduced cognitive capacity - such as delayed word recall or orientation - enter the health index negatively which may point to some barriers in access or insufficient availability of treatments for individuals suffering cognitive impairments. By and large, the estimation results are similar for both men and women, although some more health controls appear statistically significant in the estimation for the somewhat larger female sample.

Figures 1 to 10 picture the relationship between socioeconomic status, background health, and health care utilization for elderly men and women from each of the ten SHARE countries. The graphical representation of each set of estimation results consists of four graphs. The first panel presents a simple (country and gender-specific) bivariate density estimate for the two key control variables, years of education, and health care need to highlight the relevant support of the data. The remaining three panels present estimates for different levels of health care utilization, i.e. "some health care utilization" $\left(Y_{i}>0\right)$, "more health care utilization" $\left(Y_{i}>3\right)$, and "heavy use of health care"

\footnotetext{
${ }^{13}$ Note that it is entirely possible to chose more refined events using the same technique. We nonetheless believe to cover the most interesting margins of health care utilization reasonably well, even if our particular choice is admittedly somewhat ad hoc striking a subjective balance between detail of information and computation time.

${ }^{14}$ Note also that it is our explicit goal to control best for differences in health care need rather than obtaining precise estimates for the aggregating indices $\beta_{G_{i}}$. We thus use a very rich set of (partially correlated) health controls rather than aiming at increased precision of our estimate for $\beta_{G_{i}}$ by making inefficient use of the data incorporating only a subset of the available background health measures in the need index $H_{i} \beta_{G_{i}}$.
} 
$\left(Y_{i}>6\right)$.

Each of the latter three panels may be used as a basis to assess horizontal equity, responsiveness and utilization intensity at different margins of health care use considered here. Specifically, there exists some horizontal inequity if the estimated probabilities feature any education gradients. Responsiveness, in turn, can be assessed by investigating the slopes of the various utilization probabilities in the direction of health care need. Finally, national differences in utilization intensity can be gauged by comparing the levels of each probability plot across countries at different levels of health care need.

We find small positive education gradients among Austrian men with low levels of health care need, gradually reversing to a negative gradient for those in high need. Moreover, while the former is most apparent at the extensive margin of care utilization, the latter becomes more pronounced at higher levels of care utilization. For women, we don't find much evidence for a positive education gradient at any level of health care need or care utilization. Yet, the slight negative education gradient at higher level of care need seems to persist. Finally, the Austria health care system appears somewhat more responsive to need differences for women than for men.

In Denmark, we don't find much evidence for pervasive education gradients in health care utilization neither. This appears to be true for sexes, and irrespective of the level of care need or utilization intensity. If anything, there seems to be a very small positive education gradient among those in high need. Moreover, the Danish health care system seems quite responsive to differences in health care need.

The French health care system appears particularly equitable and responsive. The only domain featuring a slight positive education gradient is the use of any health care among the healthy which seems somewhat more pronounced for men than for women.

The German utilization profiles appear comparatively bumpy. For men, the overall allocation appears reasonably equitable, although we find some evidence for positive education gradients among the healthy at the extensive margin. Furthermore, there appears to be a steep upward sloping part in the very left tail of the education distribution. It is important to keep in mind that there is only very limited data falling into this range, though. Over most of the data support, the utilization profile appears quite flat in education with just a light dint. Similarly, the profiles for women in Germany do not seem to exhibit much of a socioeconomic gradient. If anything, utilization rates conditional on health appear slightly downward sloping. In addition, the estimates for Germany indicate a fair amount of responsiveness.

In Greece, we estimate a very steep positive education gradient in health care utilization for very low education levels, especially among those in comparatively high care need. This pattern then tends to reverse to a negative gradient as education levels increase. Interestingly, we find the exact reverse utilization pattern for respondents in low health care need, who feature lower levels of overall care utilization though. The latter dint is especially apparent at the extensive margin. Greece thus provides a good example of a country for which we would measure a low level of overall inequity, with typical summary measures masking considerable education gradients at different levels of health care need.

In Italy, any education gradients in health care utilization are also strongly affected by the respective level of health care need. Specifically, we find considerable positive education gradients for the more healthy respondents, especially at lower levels of care utilization. These education gradients 
gradually become negative as we move toward higher levels of health care need. The Italian system is also estimated to be fairly responsive, yet much more so for respondents with low educational attainment than for those with many years of schooling, reflecting the aforementioned reversal of the education gradient.

The Dutch health care system, on the other hand, does not appear to feature any pronounced systematic socioeconomic gradient, with the only possible exception of a slightly upward-sloping probability of any care utilization among respondents with little health care needs, especially men. Apart from some minor humps and bumps, health care utilization in the Netherlands seems very equitable and reasonably responsive overall.

The Spanish health care system appears fairly equitable, too. However, we find some indication of a small positive gradient in the left tail of the education distribution that gradually reverses to eventually feature a negative slope. For men, there is once again evidence for a more pronounced positive gradient at the extensive margin amongst the healthy respondents. The Spanish health care system also appears adequately responsive, with differences in health care need being the main driving force behind differing utilization patterns.

A particular characteristic of the Swedish system is the low overall use of health care. This is especially remarkable as the underlying estimates are conditional on health care need, which does not appear to be systematically lower in Sweden. At the same time, the Swedish health care system seems fairly equitable and responsive. We only find small positive education gradients for most levels of health care need and measures of utilization intensity. Particularly, we again find a slight positive gradient in any health care utilization amongst the most healthy respondents, this time for both men and women.

Lastly, we turn to our analysis for Switzerland. Apart from being responsive, the Swiss health care system also appears to feature small positive education gradients. Contrary to most of the other countries, however, the estimated education gradient seems more pronounced in the middle and right tail of the care need distribution than for the most healthy respondents. Particularly, we do not find a strong gradient in any health care utilization for healthy men in Switzerland though there is some evidence for such a gradient among female respondents.

As can be seen from the figures, all ten European health care systems seem both equitable and responsive. While the actual use of health care varies substantially according to health care need, there is little evidence on socioeconomic inequity in utilization, once health care need has been taken into account. If anything, there seems to be a slight tendency for some countries to feature small educational gradients in "any health care use" amongst those with low health care need. Thus, there appears to be some suggestion of higher care use amongst the better educated healthy elderly compared to their less educated (healthy) counterpart, possibly reflecting differential use of preventive health care or regular check-ups. In addition, there also appear to be some small education gradients in health care utilization amongst the more needy. In the latter case, the resulting gradient tends to be negative, indicating higher care use amongst the less education members of society.

Aggregating the information via partial mean estimation for different education levels leads to similar conclusions. Figure 11 presents such estimates fixing education at the 10th, 50th and 90th percentile of each countries' gender-specific distribution of educational attainment. We once again consider the above three intensity levels of health care utilization, though this time integrating out 
the marginal distribution of health care need. Overall, we find little, if any, evidence for horizontal inequity in health care utilization for all countries considered, a likely reflection of the universal or near-universal health insurance coverage across all ten countries (see OECD (2004)).

Figure 12 presents corresponding partial mean estimates for fixed levels of health care need on care utilization to provide an overall assessment of responsiveness and cross-country differences treatment intensity. We plot partial mean estimates for the 10th, 50th and 90th percentile of the global but gender-specific cross-country distribution of the health care index, thus fixing health care need to the same gender-specific level in each of the ten countries. Firstly, all ten health care systems display a fair amount of responsiveness to differences in care need: More needy individuals receiving more care in all countries and irrespective of which measure of treatment intensity we consider. At the same time, there appear to be notable differences in treatment intensity across countries, even when we control for possible differences health care need. For example, we find pronounced cross-country differences in "any health care utilization" $\left(Y_{i}>0\right)$ amongst those in very good health. Moreover, it is noteworthy that care utilization is particularly low in Sweden, a country with comparatively large copayments relative to the others that we consider (see OECD (2004)).

\section{Discussion}

The present study analyzes socioeconomic and medical determinants of health care utilization of individuals aged 50+ from ten European countries. The paper advances recently developed tools and concepts from the literature on semi- and nonparametric econometrics to assess horizontal equity, responsiveness and cross-country intensity variation in the number of doctor visits of European elderly. The use of properly comparable international health data from the first wave of SHARE facilitates sensible cross-country comparisons while simultaneously allowing for a comprehensive assessment of differential responsiveness across health care systems. We employ recent advances in semiparametric econometrics to unfold the interplay of socioeconomic status and health care need in the determination of health care utilization in different institutional settings. Particularly, these allow for the use of multiple background health proxies to cover numerous aspects of health care need without compromising cross-national comparability or relying on excessive parameterization. By and large, European health care systems appear both equitable and responsive. If anything, there appears to be some evidence for a more widespread positive education gradient in some health care use among the healthy elderly. We do, however, find considerable variation in the overall intensity of health care utilization across countries, even after accounting for possible differences in health care need. Hence, while there appear to be international differences in the overall use of health care among the European elderly, these do not seem to be systematically related to socioeconomic status or substantially compromise the responsiveness of the system. 


\section{Appendix}

\section{A1: Estimation Procedure}

\section{A1.1: Semiparametric Likelihood}

This appendix presents some technical details regarding the estimator used. Both estimation strategy and corresponding notation closely follow Klein and Spady (1993), Klein and Sherman (2002), Klein and Vella (2004) and Maurer, Klein and Vella (2006) respectively.

Consider the probability of a binary event of the form $\left\{Y_{i}>c_{j}\right\}, c_{j} \in C$.

Let

$$
\begin{aligned}
P_{C_{i} G_{i}}^{i j}\left(\beta_{G_{i}}\right) & \equiv P_{C_{i} G_{i}}\left(Y_{i}>c_{j} \mid S_{i}, H_{i} \beta_{G_{i}}\right) \\
& =\frac{f_{0 C_{i} G_{i}}^{j}\left(S_{i}, H_{i} \beta_{G_{i}}\right)}{\left(f_{0 C_{i} G_{i}}^{j}\left(S_{i}, H_{i} \beta_{G_{i}}\right)+f_{1 C_{i} G_{i}}^{j}\left(S_{i}, H_{i} \beta_{G_{i}}\right)\right)}
\end{aligned}
$$

with $f_{s C_{i} G_{i}}^{j}\left(S_{i}, H_{i} \beta_{G_{i}}\right)$ denoting the joint density of $\left(S_{i}, H_{i} \beta_{G_{i}}\right)$ conditional on $I\left\{Y_{i}>c_{j}\right\}, c_{j} \in C=$ $s$ with $s=0$ and $s=1$ respectively. Replacing these densities by their nonparametric estimates, we obtain an (estimated) quasi-likelihood function of the form

$$
\hat{L}(\phi) \equiv \frac{1}{N} \sum_{i=1}^{N} \hat{l}_{i}(\phi)
$$

with

$$
\hat{l}_{i t}(\phi) \equiv \hat{\tau}_{i t}\left(\sum_{j=1}^{K} I\left\{c_{j-1}<Y_{i} \leq c_{j}\right\} \operatorname{Ln}\left[\widehat{P}_{C_{i} G_{i}}^{i j-1}\left(\beta_{G_{i}}\right)-\widehat{P}_{C_{i} G_{i}}^{i j}\left(\beta_{G_{i}}\right)\right]\right)
$$

where $\tau_{i t}$ denotes a trimming function and hats indicate estimates. The following paragraphs indicate the basic assumptions needed to obtain a version of the quasi-likelihood function that can be used as if it were the true underlying likelihood. Note that the actual estimation is performed by gender based on the stacked quasi-likelihoods for all countries. However, we suppress the dependence of the below objects on country and gender for notational convenience. The below estimation details can be used to construct the quasi-likelihood for each country-gender interaction separately. Stacking the country-specific quasi-likelihoods by gender then results in the two overall quasi-likelihood functions which are maximized for each gender separately. The following paragraphs detail the assumptions under which we may replace the true likelihood by the above quasi-likelihood in the estimations.

Assumption A1: Pilot Density Estimators. Let $K$ be a symmetric, smooth univariate kernel function satisfying condition $C 8$ in Klein and Spady (1993, p. 394). In this paper, we use a normal kernel that satisfies this condition. For fixed and small $\delta: 0<\delta<\frac{1}{12}$, select a $\alpha$ such that $\frac{1}{12}<\alpha<\frac{1}{(10+\delta)}$. The pilot bandwidth is given by $h_{p} \equiv\left(N_{C_{i} G_{i}}\right)^{-(2 / 3) \alpha}$, where $N_{C_{i} G_{i}}$ denotes the number of observations of the specific country-gender cell considered here. Let $Z$ be a matrix such that $Z_{j s}^{\prime} Z_{j s}=\hat{\Sigma}_{j s}\left(\beta_{G_{i}}\right)$, the inverse of the sample covariance matrix of $\left(S_{i}, H_{i} \beta_{G_{i}}\right)$ for observations with $I\left\{Y_{i}>j\right\}=s$ with $s=0$ and $s=1$ respectively. Partitioning $Z_{j s}=\left[Z_{1 j s} Z_{2 j s}\right]^{\prime}$ conformably 
with $\left(S_{i}, H_{i} \beta_{G_{i}}\right)$, we define

$$
k_{i k}^{j s}(h, \varphi) \equiv \frac{\operatorname{det}\left(\hat{\Sigma}_{j s}(\phi)\right)^{-1 / 2}}{[\varphi h]^{2}} K\left(\frac{Z_{1 j s}\left(S_{i}-S_{k}\right)}{\varphi h}\right) K\left(\frac{Z_{2 j s}\left(H_{i} \beta_{G_{i}}-H_{k} \beta_{G_{i}}\right)}{\varphi h}\right)
$$

We can then define the pilot estimator for $g_{C_{i} G_{i}}^{j}\left(S_{i}, H_{i} \beta_{G_{i}}\right)$ as:

$$
\hat{\pi}_{j s}^{i} \equiv \frac{1}{N} \sum_{k} s k j_{i k}^{s}\left(h_{p}, 1\right), s=0,1
$$

Pilot density estimation of $f_{C_{i} G_{i}}^{j}\left(S_{i}, H_{i} \beta_{G_{i}}\right)$ proceeds analogously.

Assumption A2: Locally Smoothing Parameters. Referring to (A1), denote $\hat{m}_{j s}$ as the geometric mean of the $\hat{\pi}_{j s}^{i}$ and let $\hat{\psi}_{s j}^{i} \equiv \frac{\hat{\pi}_{j s}^{i}}{\hat{m}_{j s}}$. We then define local smoothing parameters as:

$$
\hat{\sigma}_{s j}^{i}=\left[\hat{d}_{s j}^{i} \hat{\psi}_{s j}^{i}+\left(1-\hat{d}_{s j}^{i}\right) / \ln \left(N_{C_{i} G_{i}}\right)\right]^{-1 / 2}
$$

where the smoothed indicator $\hat{d}_{s j}$ is given by

$$
\hat{d}_{s j}^{i} \equiv\left[1+\exp \left(-\left(N_{C_{i} G_{i}}\right)^{\varepsilon}\left[\hat{\psi}_{s j}^{i}-\frac{1}{\ln \left(N_{C_{i} G_{i}}\right)}\right]\right)\right]^{-1}
$$

with $\alpha$ and $\delta$ as in assumption (A1) and $\varepsilon: 0<\varepsilon<\frac{1}{4}(\alpha-\delta)$.

Assumption A3: Second Stage (Locally Smoothed) Density Estimators. For $\alpha$ given as in (A1), define a global window component $h \equiv N_{C_{i} G_{i}}^{-\alpha}$. With $\hat{\sigma}_{s j}^{i}$ as the vector of local smoothing parameters in (A2) and with $k_{i k}^{j s}(h, \varphi)$ defined as in (A1), we obtain a locally-smoothed estimator for $f_{s C_{i} G_{i}}\left(S_{i}, H_{i} \beta_{G_{i}}\right)$ given by

$$
\hat{f}_{s C_{i} G_{i}}\left(S_{i}, H_{i} \beta_{G_{i}}\right)=\frac{1}{N_{C_{i} G_{i}}} \sum_{j} s k_{i k}^{j s}\left(h, \hat{\sigma}_{s j}^{i}\right), s=0,1 .
$$

Assumption A4: Semiparametric Probability Function. We now obtain an estimate for the above semiparametric probability function as:

$$
\widehat{P}_{C_{i} G_{i}}^{i j}\left(\beta_{G_{i}}\right) \equiv \frac{\widehat{f}_{0 C_{i} G_{i}}^{j}\left(S_{i}, H_{i} \beta_{G_{i}}\right)}{\left(\widehat{f}_{0 C_{i} G_{i}}^{j}\left(S_{i}, H_{i} \beta_{G_{i}}\right)+\widehat{f}_{1 C_{i} G_{i}}^{j}\left(S_{i}, H_{i} \beta_{G_{i}}\right)\right)}
$$

which we can use to construct the (estimated) quasi-likelihood $\hat{L}\left(\beta_{G_{i}}\right)$.

We then obtain semiparametric maximum likelihood estimates for the normalized index coefficients as

$$
\widehat{\beta}_{G_{i}} \equiv \underset{\beta_{G_{i}}}{\arg \max } \hat{L}\left(\beta_{G_{i}}\right) \equiv \underset{\beta_{G_{i}}}{\arg \max } \frac{1}{N_{G_{i}}} \sum_{i \in G_{i}} \hat{l}_{i t}\left(\beta_{G_{i}}\right)
$$

with $N_{G_{i}}=\sum_{C} N_{C_{i} G_{i}}$. 


\section{A1.2: Partial Mean Estimation}

We estimate partial means similar to the average structural function (ASF) where the mean is taken with respect to one argument's marginal rather than conditional distribution. Originally, estimation of the ASF has been suggested for nonseparable models featuring endogeneity to eliminate the effect of a correlated error term when estimating the effect of an endogenous regressor on a particular outcome of interest (see Chamberlain (1984) or Blundell and Powell $(2001,2004)$. We define the partial mean for education $P M S$ as

$$
P M S_{C G}(S)=\int D V_{C G}\left(S, H \beta_{G}\right) d F_{H \beta_{G}}
$$

while the partial mean for health $P M H$ is analogously defined as

$$
P M H_{C G}\left(H \beta_{G}\right)=\int D V_{C G}\left(S, H \beta_{G}\right) d F_{S}
$$

where $F_{H \beta_{G}}$ and $F_{S}$ denote the marginal distribution of $H \beta_{G}$ and $S$ respectively.

Both objects can be estimated using the analogy principle, replacing true distributions by their corresponding sample counterparts. Hence, we estimate the partial mean for education by

$$
\widehat{P M} S_{C G}(S)=\int D V_{C G}\left(S, H \widehat{\beta}_{G}\right) d \widehat{F}_{H \widehat{\beta}_{G}}
$$

and the partial mean for health analogously by

$$
\widehat{P M} H_{C G}\left(H \widehat{\beta}_{G}\right)=\int D V_{C G}\left(S_{i}, H \widehat{\beta}_{G}\right) d \widehat{F}_{S}
$$

where $\widehat{F}_{H \beta_{G}}$ and $\widehat{F}_{S}$ denote the empirical marginal distribution of $H \widehat{\beta}_{G}$ and $S$ respectively. 


\section{References}

Adler, N, McEwen, B, Stewart, J, Marmot, M (eds) 2000, Socioeconomic status and health in industrial nations: social, psychological, and biological pathways, Annals of the New York Academy of Sciences: New York.

Adler, N, Newman, K 2002, Socioeconomic disparities in health: pathways and policies, Health Affairs, 21: $60-76$.

Blundell, R, Powell, J 2001, Endogeneity in nonparametric and semiparametric regression models. Cemmap Working Paper CWP 09/01.

Blundell, R, Powell, J 2004, Endogeneity in semiparametric binary response models. Review of Economic Studies, 71: 655-679.

Börsch-Supan, A, Brugiavini, A, Jürges, H, Mackenbach, J, Siegrist, J, Weber, G (eds) 2005, Health, ageing and retirement in Europe - first results from the survey of health, ageing and retirement in Europe; MEA Mannheim.

Börsch-Supan, A, Jürges, H (eds) 2005, Health, ageing and retirement in Europe - methodology; MEA Mannheim.

Chamberlain, G 1984, Panel data. In Handbook of Econonometrics, Volume 2, Griliches Z, Intrilligator M (eds). Elsevier Science: Amsterdam, 1247-1320.

Case, A, Deaton, A 2005, Broken down by work and sex: how our health declines. In Analyses in the Economics of Aging. David Wise (ed). University of Chicago Press: Chicago, 185-205.

Cutler, D, Lleras-Muney, A 2006, Education and health: evaluating theory and evidence. NBER Working Paper No. 12352.

Deaton, A 1997, The Analysis of Household Surveys: A Microeconometric Approach to Development Policy. Johns Hopkins University Press: Baltimore.

Deaton, A 2003, Health, inequality, and economic development. Journal of Economic Literature, 41: $113-158$.

Goldman, D, Smith, J 2002, Can patient self-management help explain the ses health gradient? Proceedings of the National Academy of Sciences, 99: 10929-10934.

Groot, W 2000, Adaption and scale of reference bias in self-assessments of quality of life. Journal of Health Economics, 19: 403-420.

Horowitz, J 1998, Semiparametric methods in econometrics. Springer: New York.

Jürges, H 2006, True health vs. response styles: exploring cross-country differences in self-reported health. forthcoming in Health Economics.

Klein, R, Sherman, R 2002, Shift restrictions and semiparametric estimation in ordered response models. Econometrica, 70: 663-691. 
Klein, R, Spady, R 1993, An Efficient Semiparametric Estimator for Binary Response Models, Econometrica 1993; 61: 387-421.

Klein, R, Vella, F 2004, A semiparametric model for binary response and continuous outcomes under index heteroscedasticity, mimeo.

Lindeboom, M, van Doorslaer, E 2004, Cut-point shift and index shift in self-reported health. Journal of Health Economics, 23: 1083-1099.

Marmot, M 2005, Status Syndrome. Bloomsbury: London.

Marmot, M, Wilkinson, R 1999, Social Determinants of Health. Oxford University Press: Oxford.

Maurer, J, Klein, R, Vella, F 2006, Health, demographics, and retirement: evidence from a semiparametric binary choice panel data model with nonadditive correlated individual-specific effects, mimeo.

OECD 2004. Towards High-Performing Health Systems, OECD: Paris.

Santos-Eggimann, B, Junod, J, Cornaz, S 2005, Health service utilization of older Europeans. In Health, Ageing and Retirement in Europe - First Results from the Survey of Health, Ageing and Retirement in Europe. Börsch-Supan A, Brugiavini A, Jürges H, Mackenbach J, Siegrist J, Weber G. (eds), MEA Mannheim, 131-140.

Sen, A 2002, Health: perception vs. observation. British Medical Journal, 324: 860-861.

Smith, J 1999, Healthy bodies and think wallets: the dual relationship between health and socioeconomic status. Journal of Economic Perspectives, 13: 145-166.

Smith, J 2003, Consequences and predictors of new health events. IFS Working Paper WP03/22.

Smith, J 2004, Unraveling the ses-health connection. Population and Development Review, 30: 108132.

Van Doorslaer, E, Koolman, X, Jones, A 2004. Explaining income-related inequalities in doctor utilisation in Europe. Health Economics, 13: 629-647.

Van Doorslaer, E, Wagstaf,f A, Rutten, F.(eds) 1993, Equity in the finance and delivery of health care: an international perspective. Oxford University Press: Oxford.

Van Doorslaer, E, Wagstaff, A, van der Burg, H, Christiansen, T, de Graeve, D, Duchesne, I, Gerdtham, U, Gerfin, M, Geurts, J, Gross, L, Häkkinen, U, John, J, Klavus, J, Leu, R, Nolan, B, O’Donnell, O., Propper, C., Puffer, F, Schellhorn, M, Sundberg, G, Winkelhage, O 2000. Equity in the delivery of health care in Europe and the US. Journal of Health Economics, 19: 553-583.

Wagstaff, A, van Doorslaer, E 2000, Equity in health care finance and delivery. In Handbook of Health Economics, Volume 1: 1803-1862, Culyer A, Newhouse J. (eds) Elsevier Science: Amsterdam. 
Table 1: Number of Observations by Country and Gender

\begin{tabular}{lcc}
\hline \hline & Men & Women \\
Austria & 720 & 893 \\
Denmark & 713 & 791 \\
France & 654 & 815 \\
Germany & 1248 & 1380 \\
Greece & 787 & 895 \\
Italy & 1017 & 1202 \\
The Netherlands & 1246 & 1359 \\
Spain & 880 & 1134 \\
Sweden & 1309 & 1397 \\
Switzerland & 414 & 445 \\
\hline Total & 8988 & 10311 \\
\hline \hline
\end{tabular}



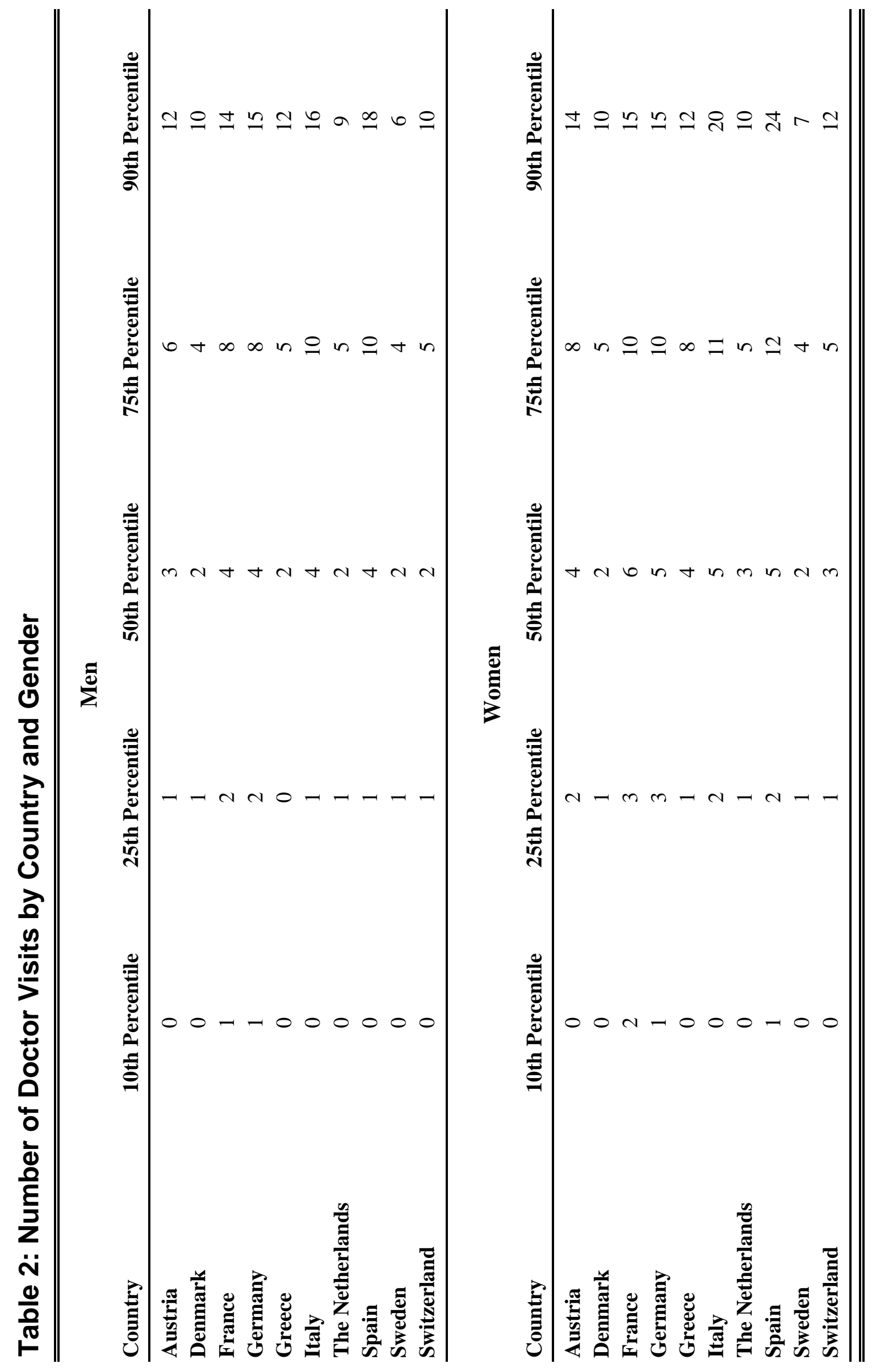


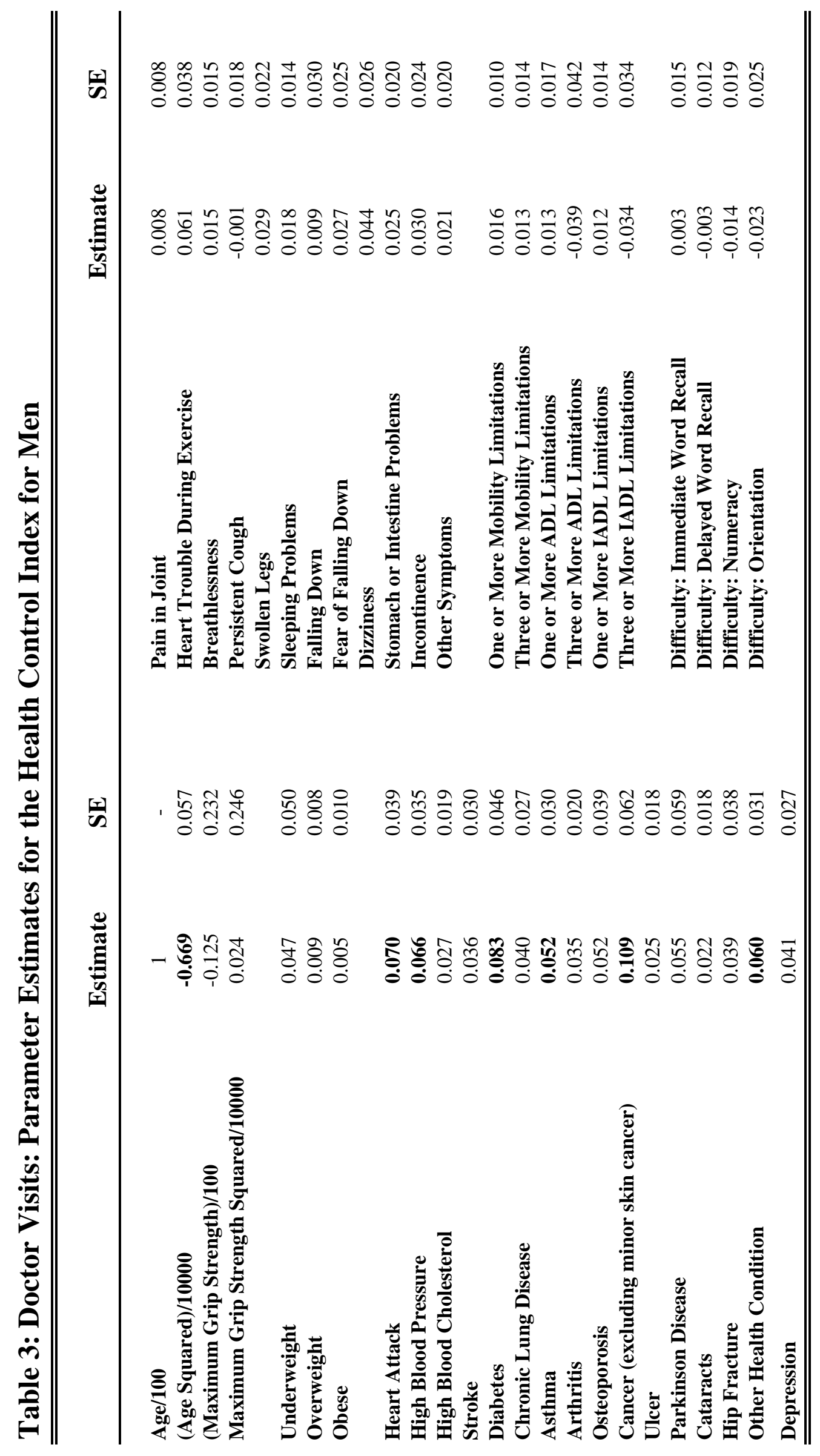




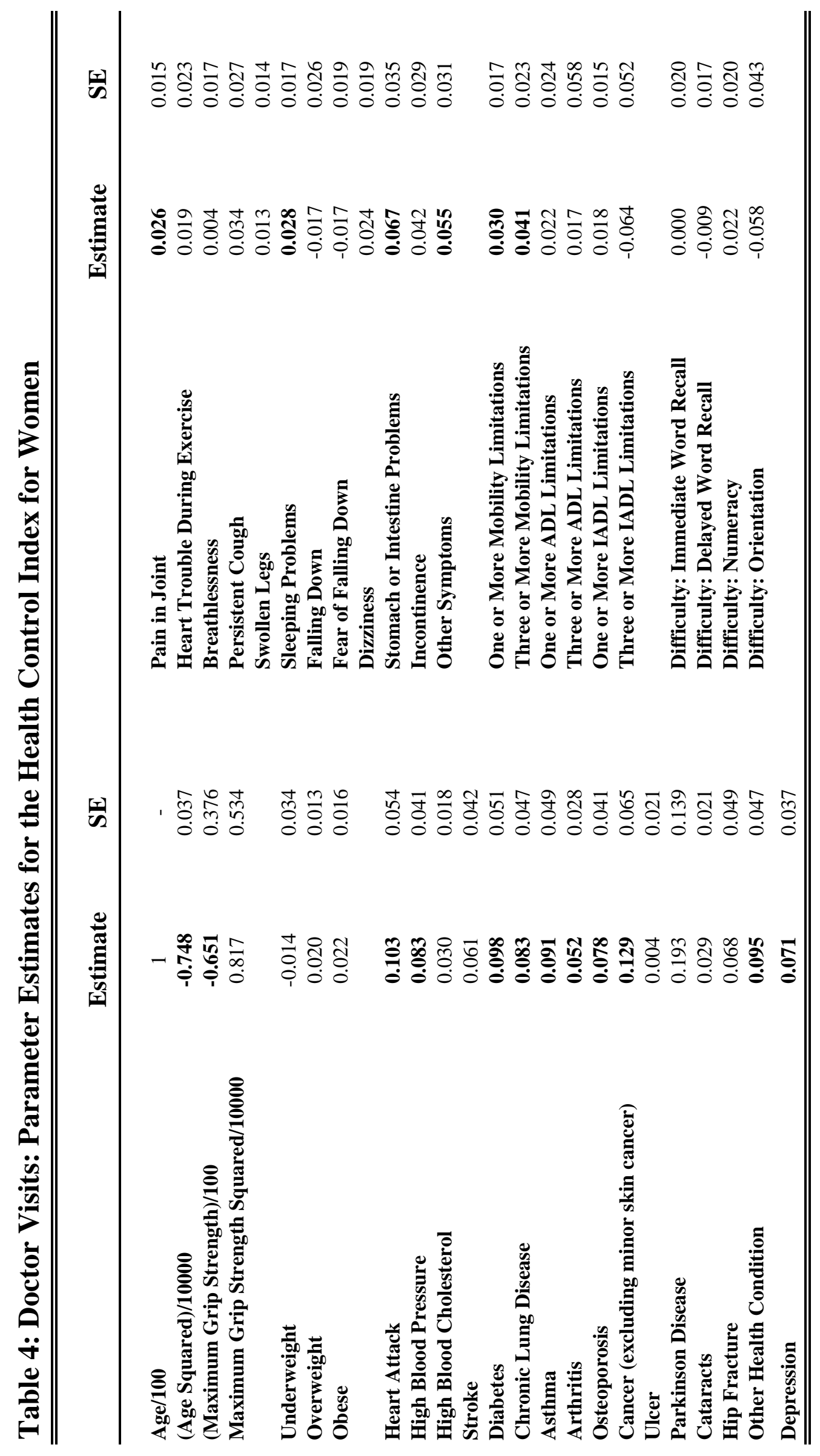


Figure 1: Health Care Utilization in Austria

A. Men
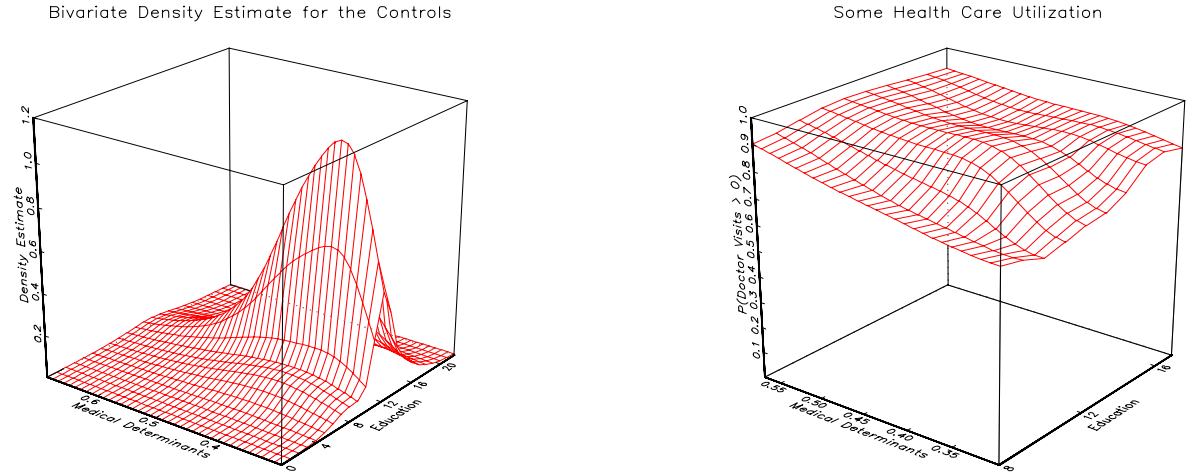

More Health Care Utilization
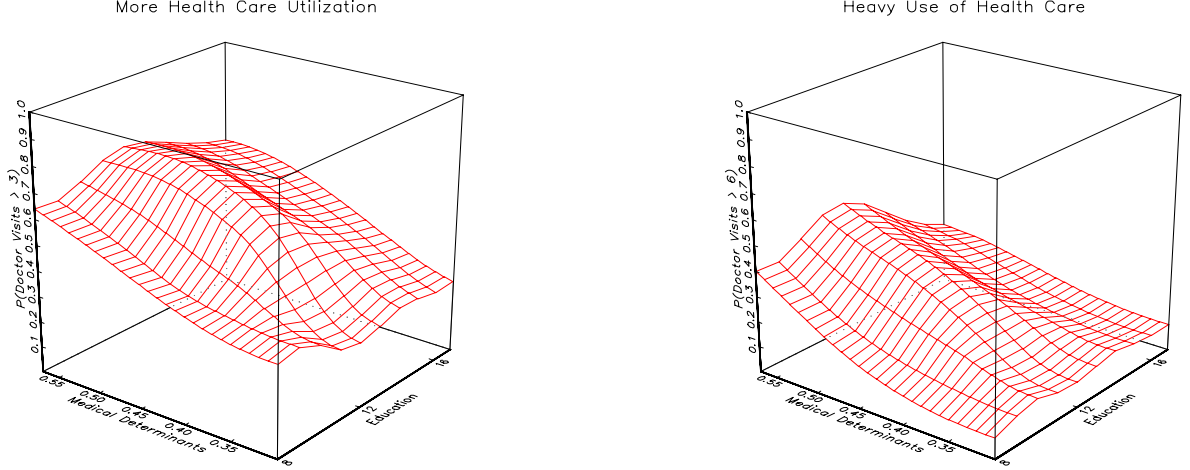

B. Women
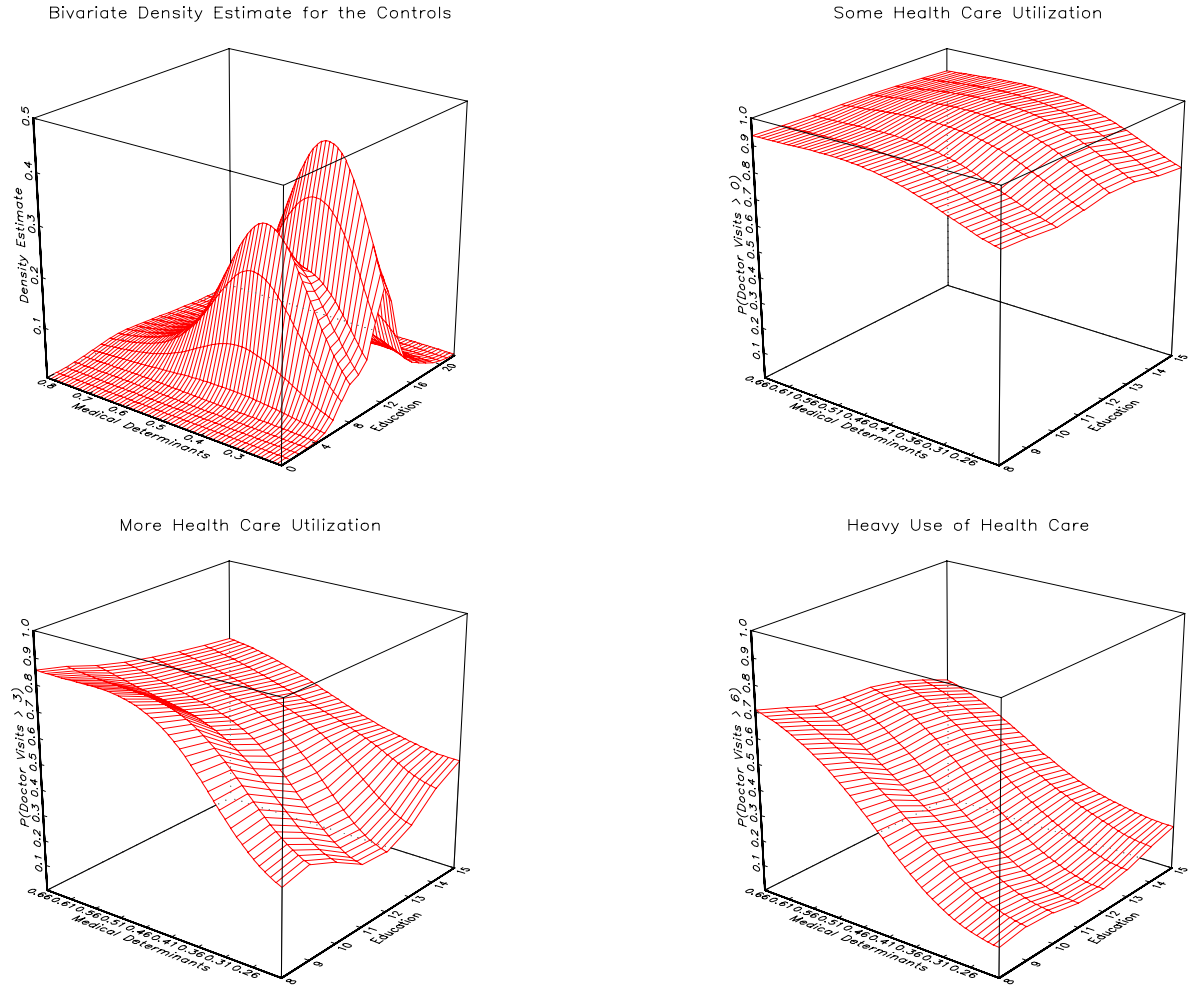
Figure 2: Health Care Utilization in Denmark

A. Men
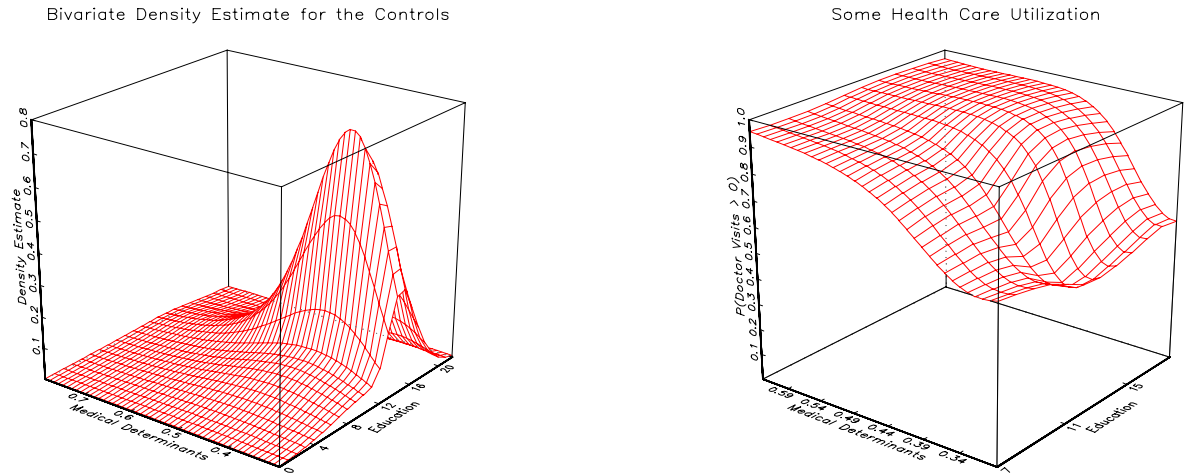

More Health Care Utilization
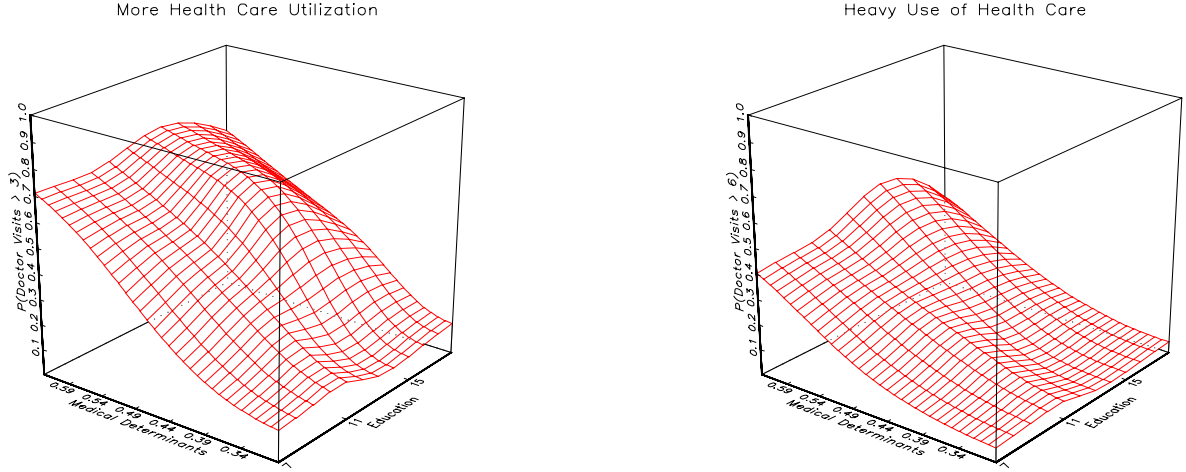

B. Women
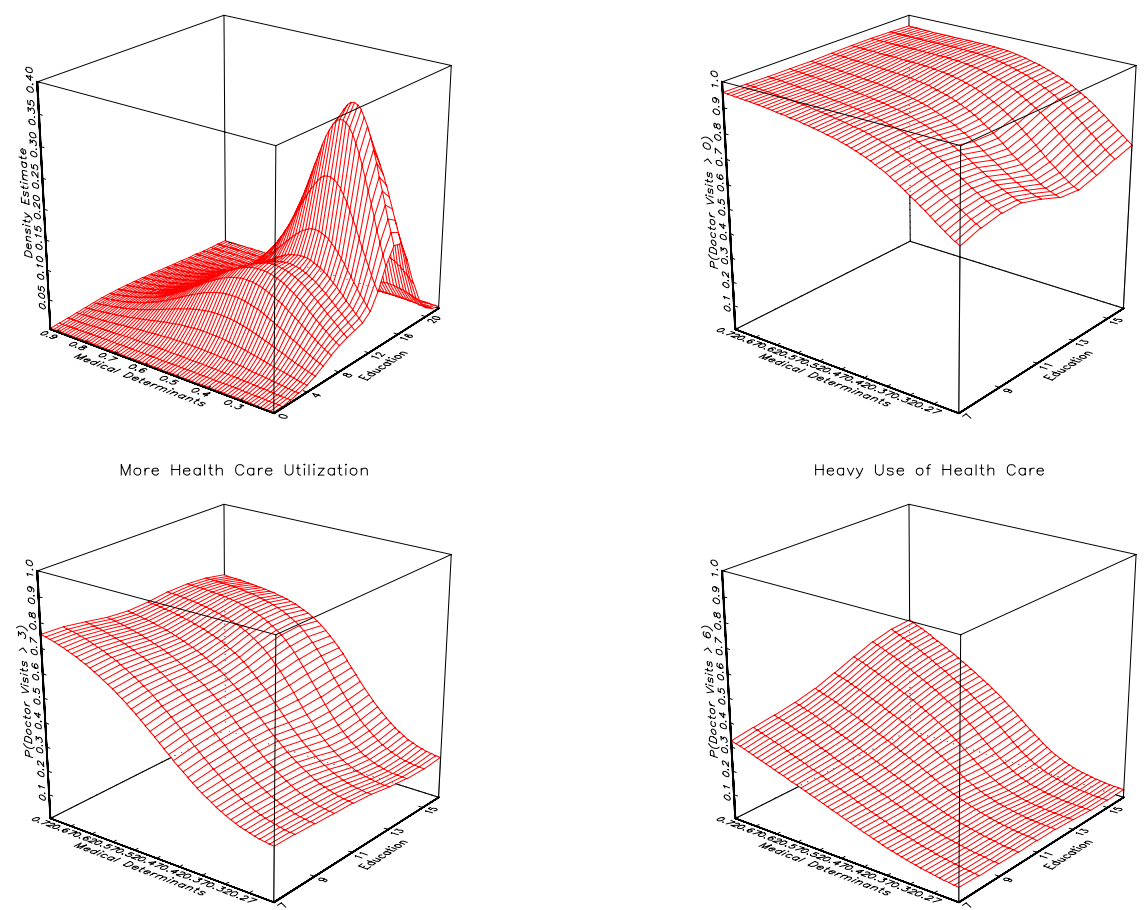
Figure 3: Health Care Utilization in France

A. Men
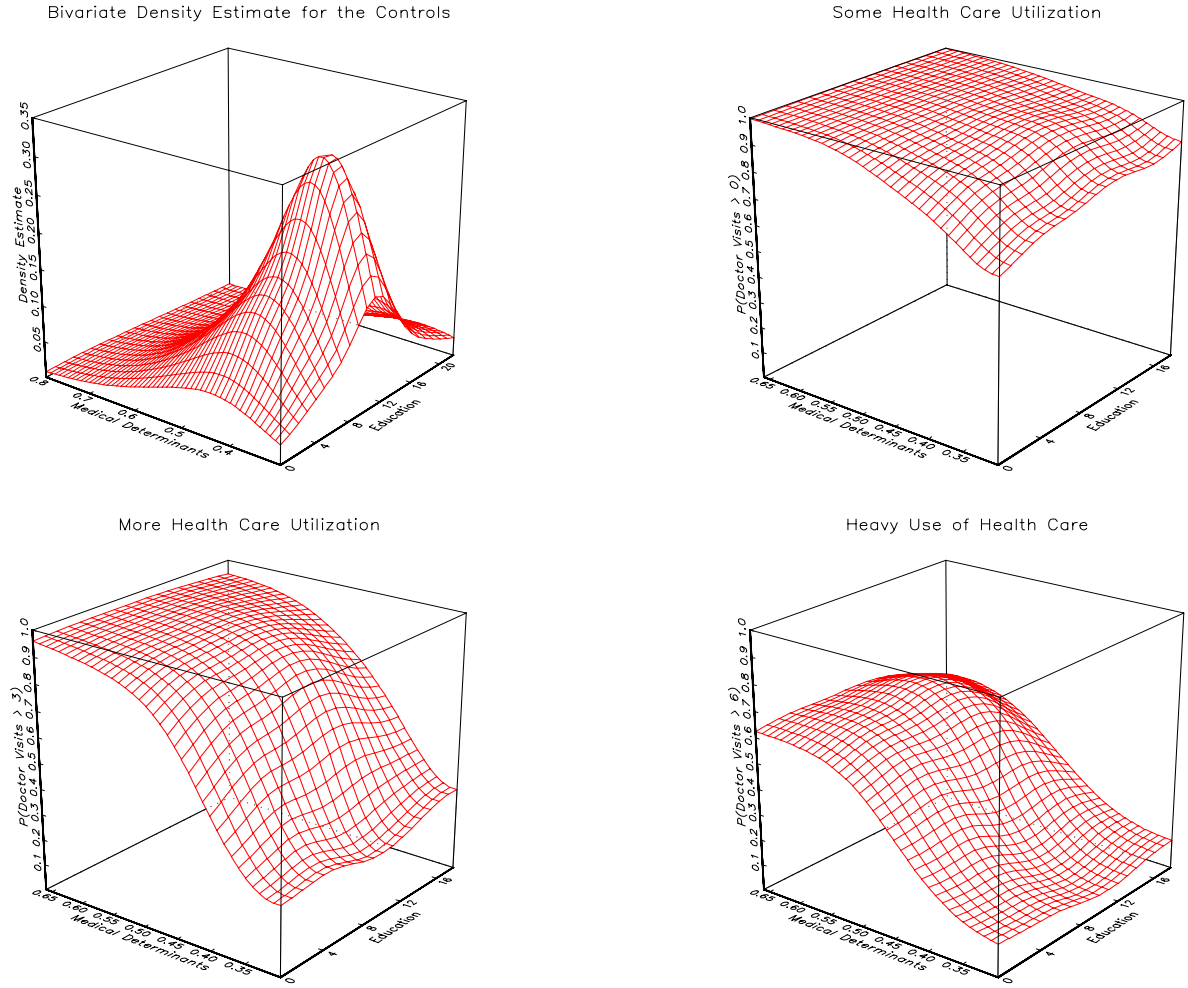

B. Women
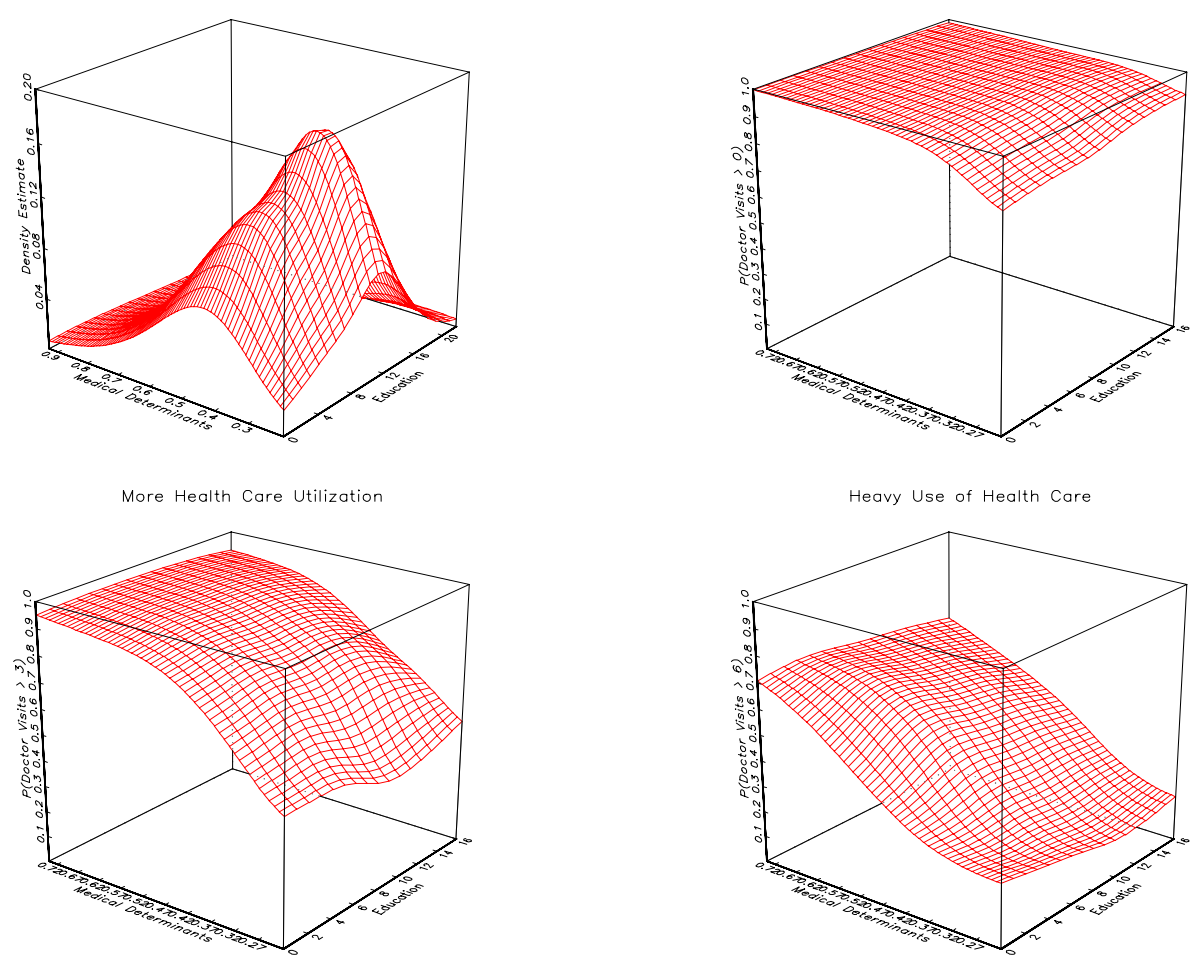
Figure 4: Health Care Utilization in Germany

A. Men
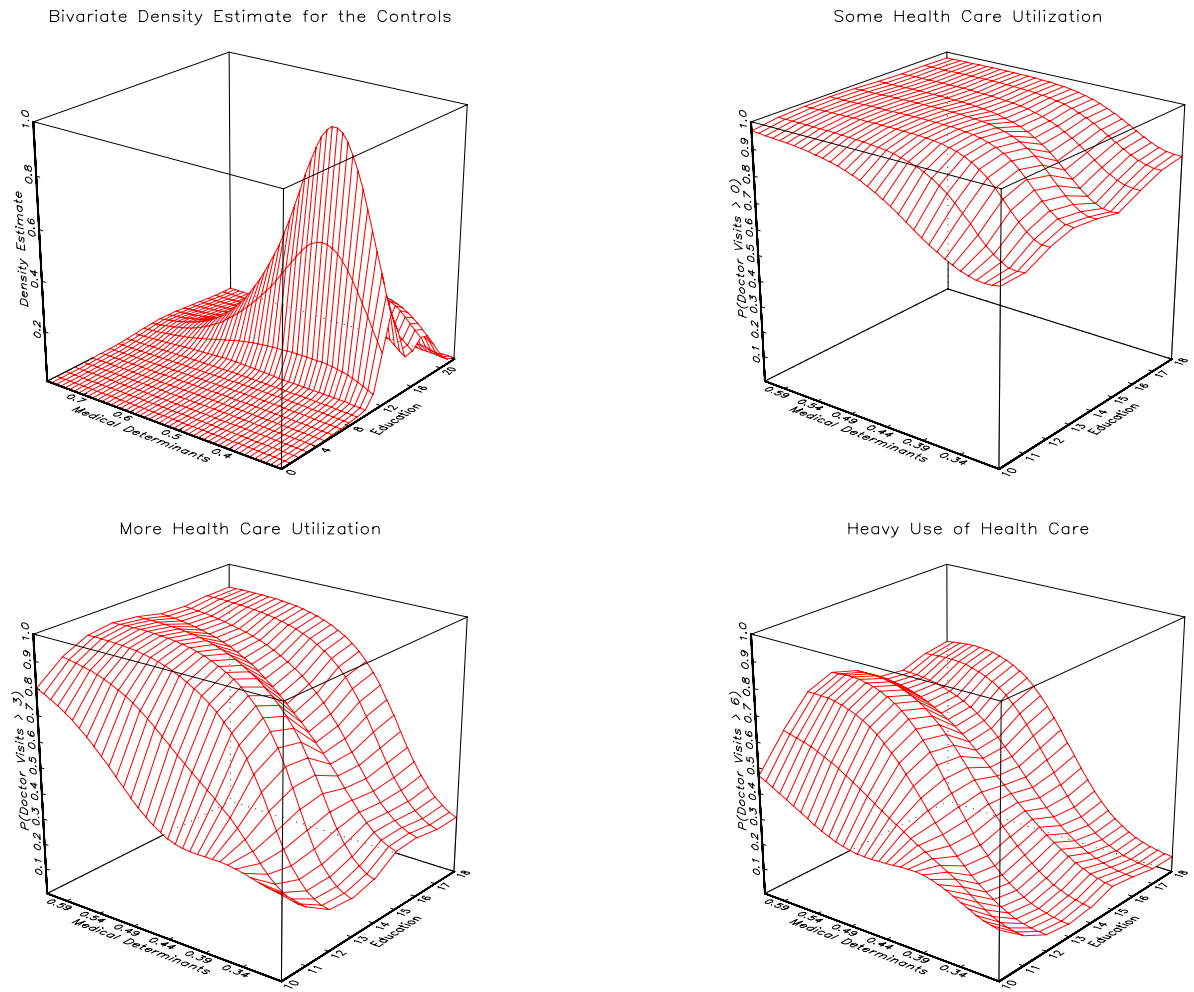

B. Women
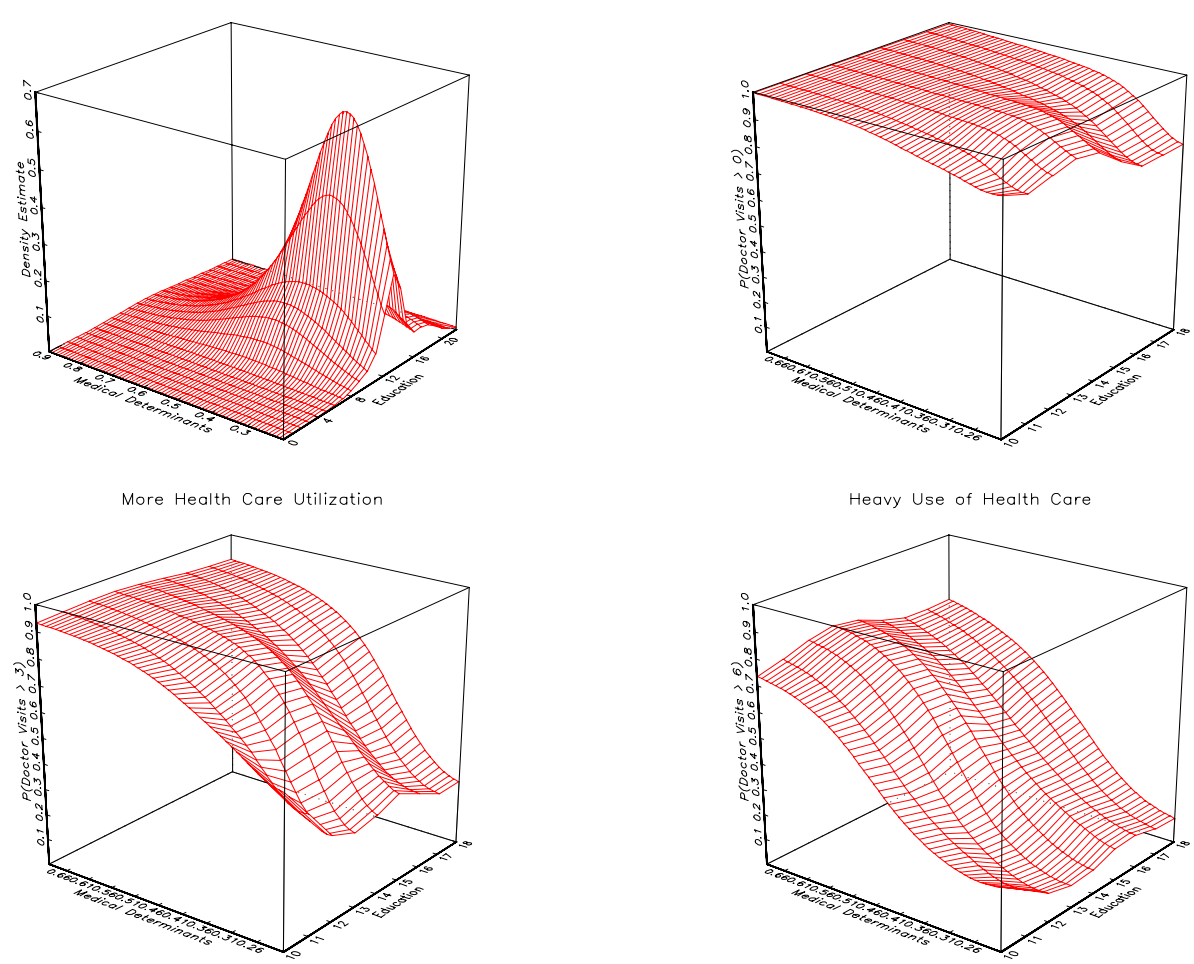
Figure 5: Health Care Utilization in Greece

A. Men
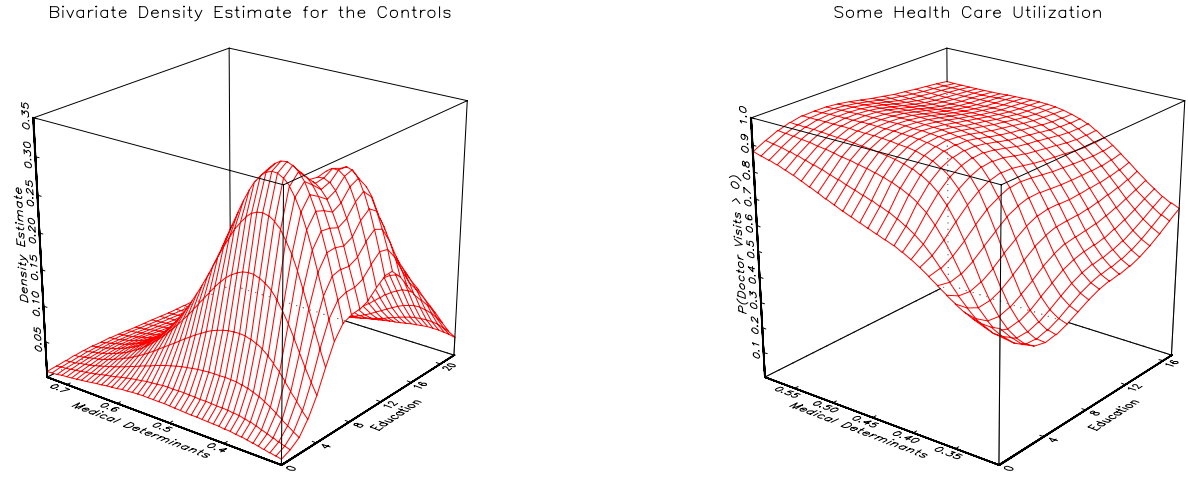

More Health Care Utilization
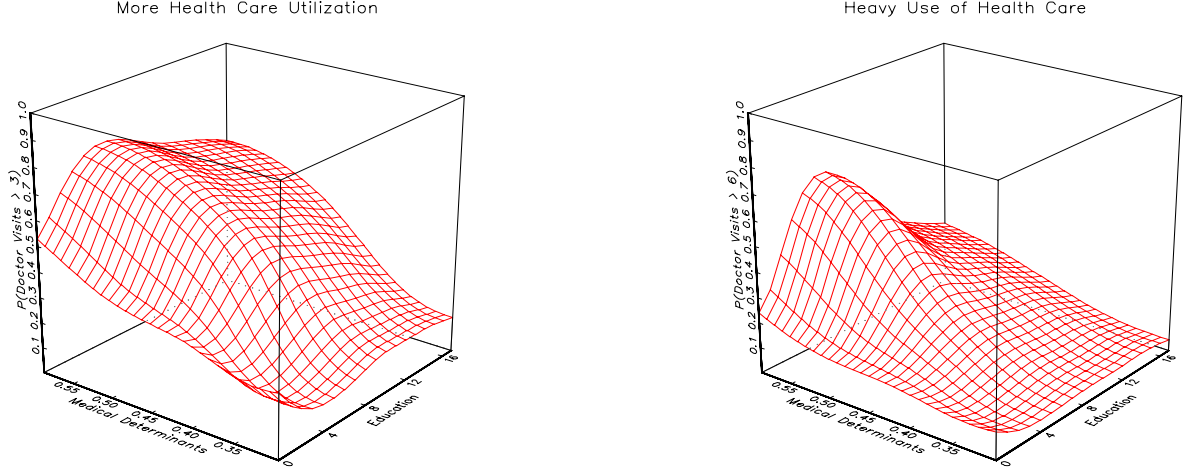

B. Women
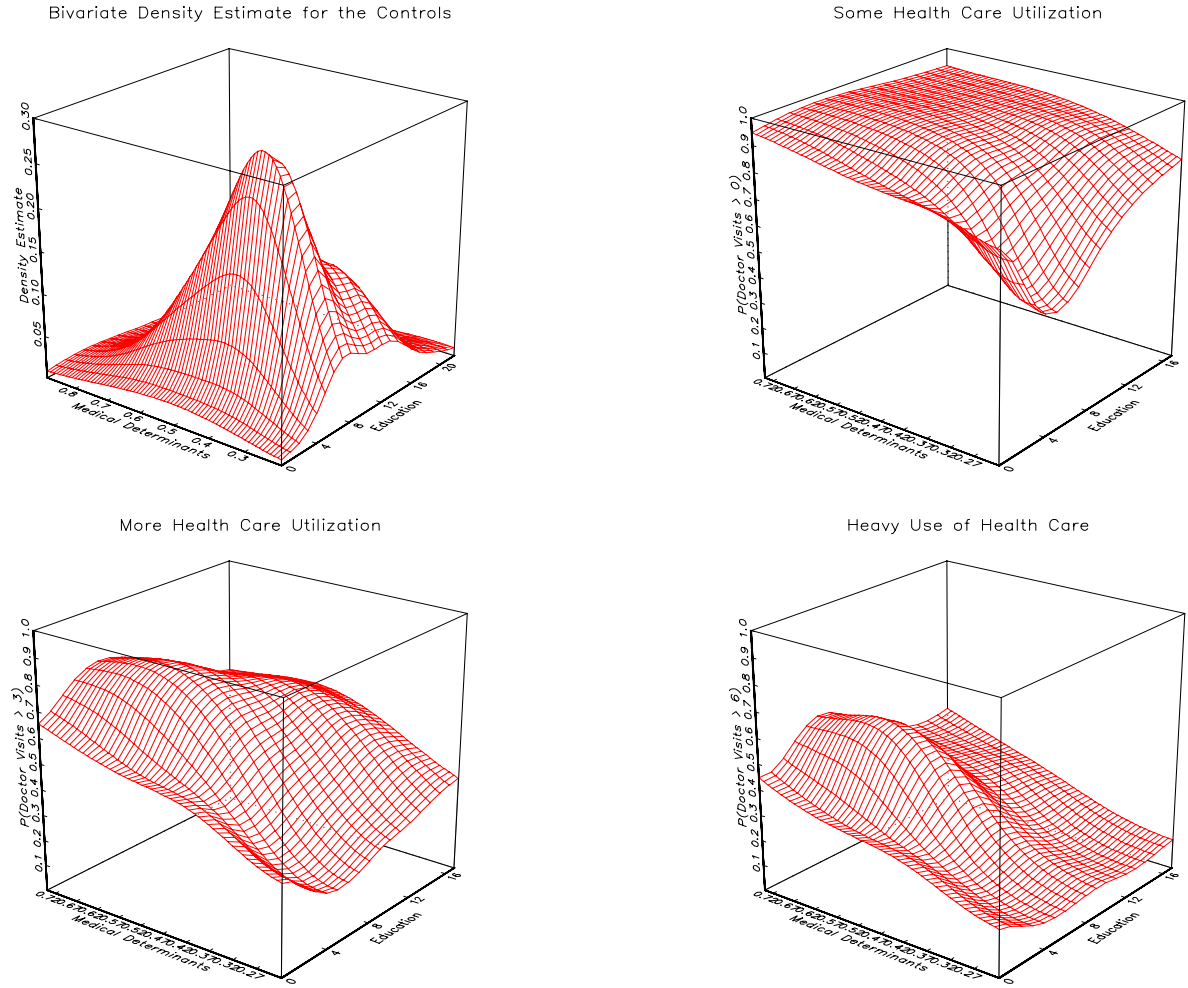
Figure 6: Health Care Utilization in Italy

A. Men
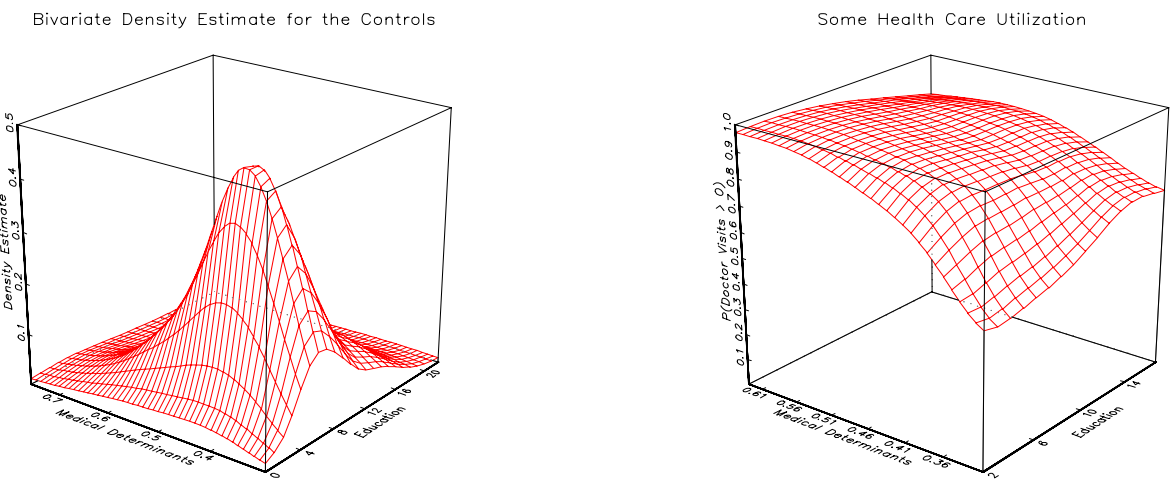

More Health Care Utilization
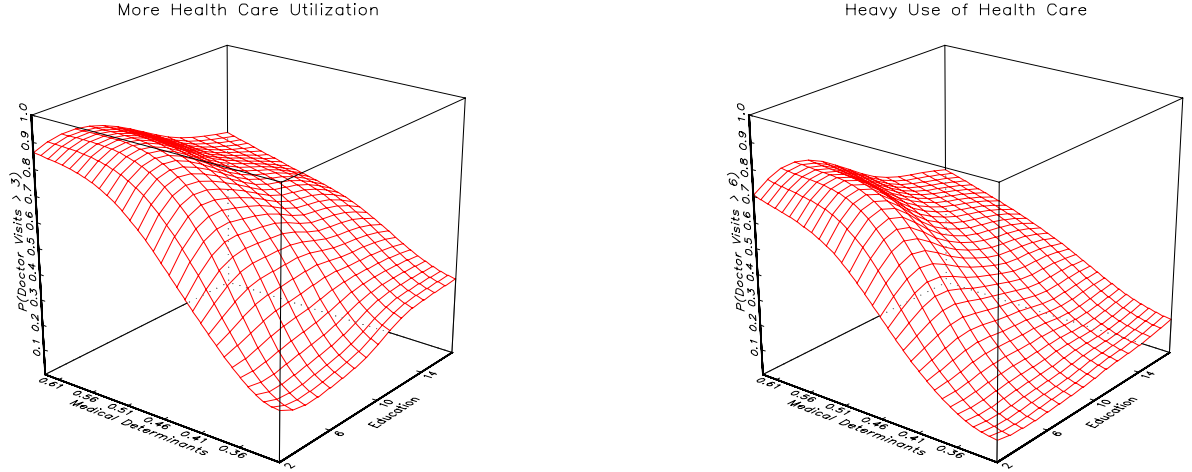

B. Women
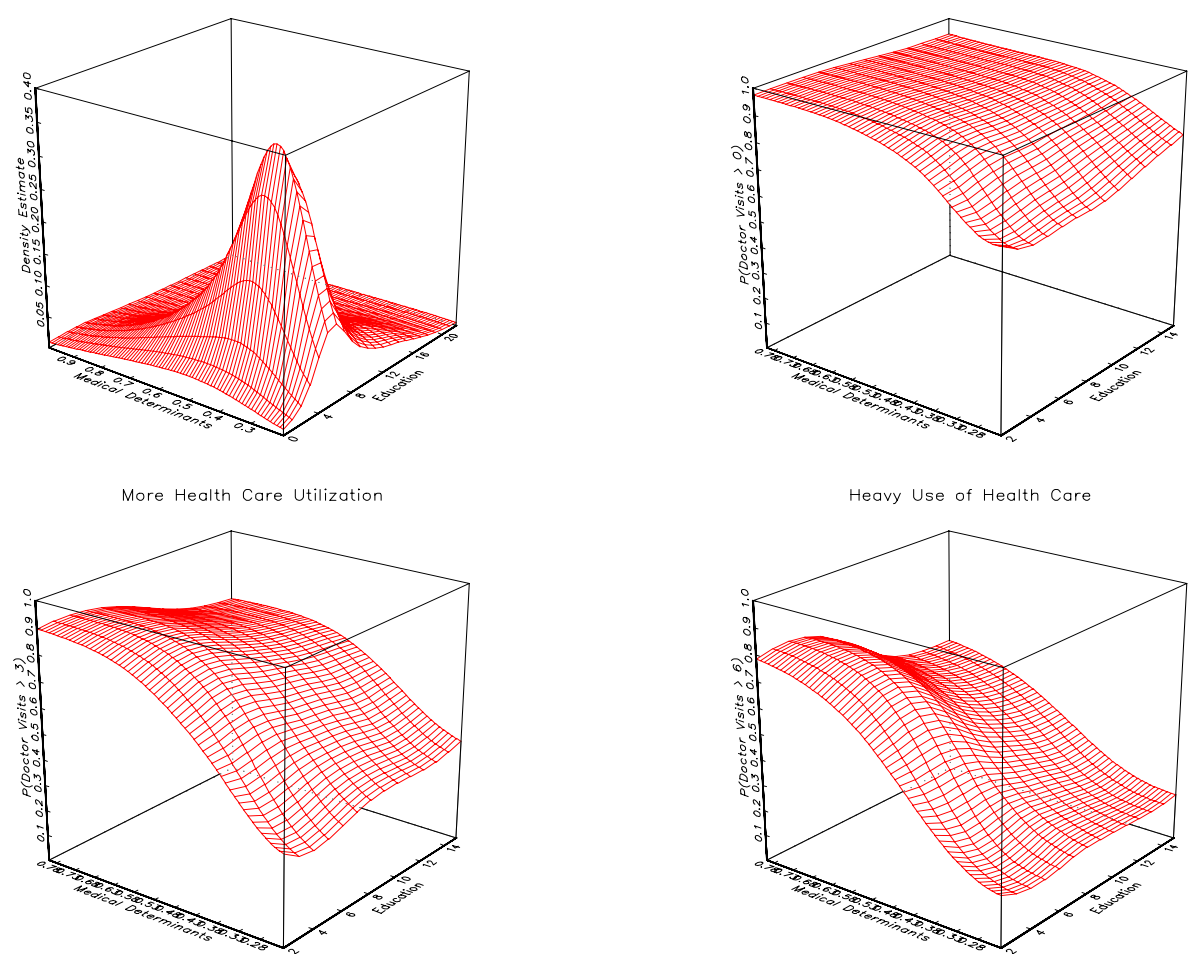
Figure 7: Health Care Utilization in the Netherlands

A. Men
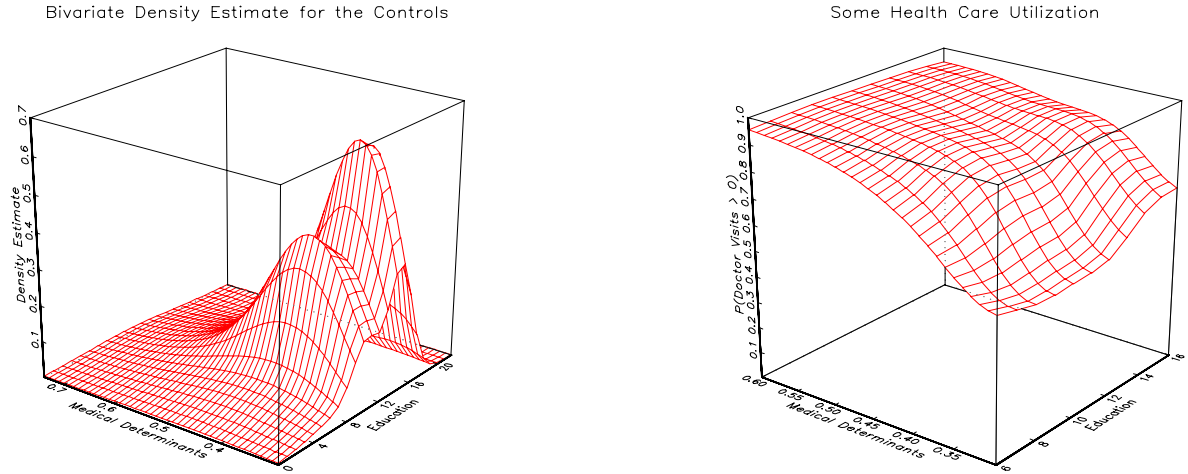

More Health Care Utilization
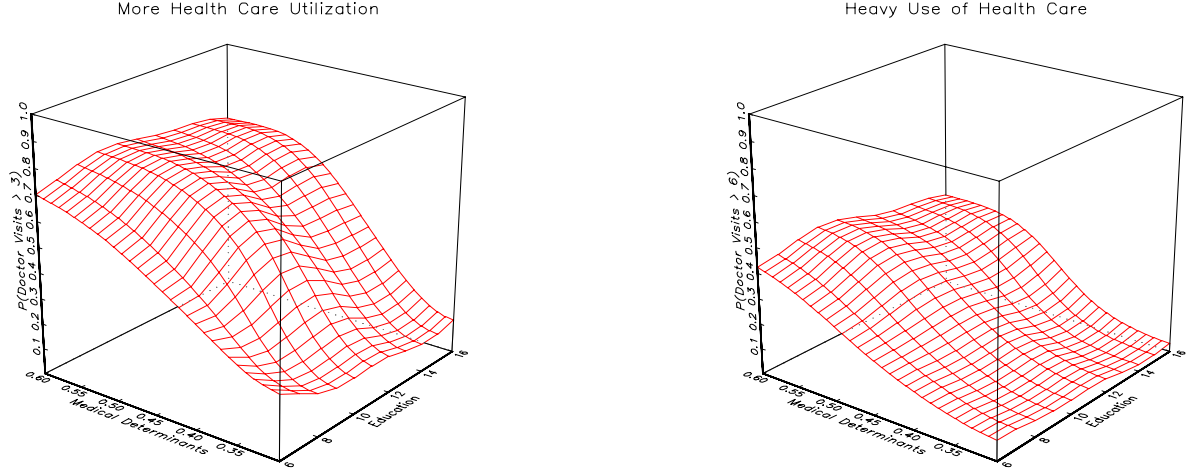

B. Women
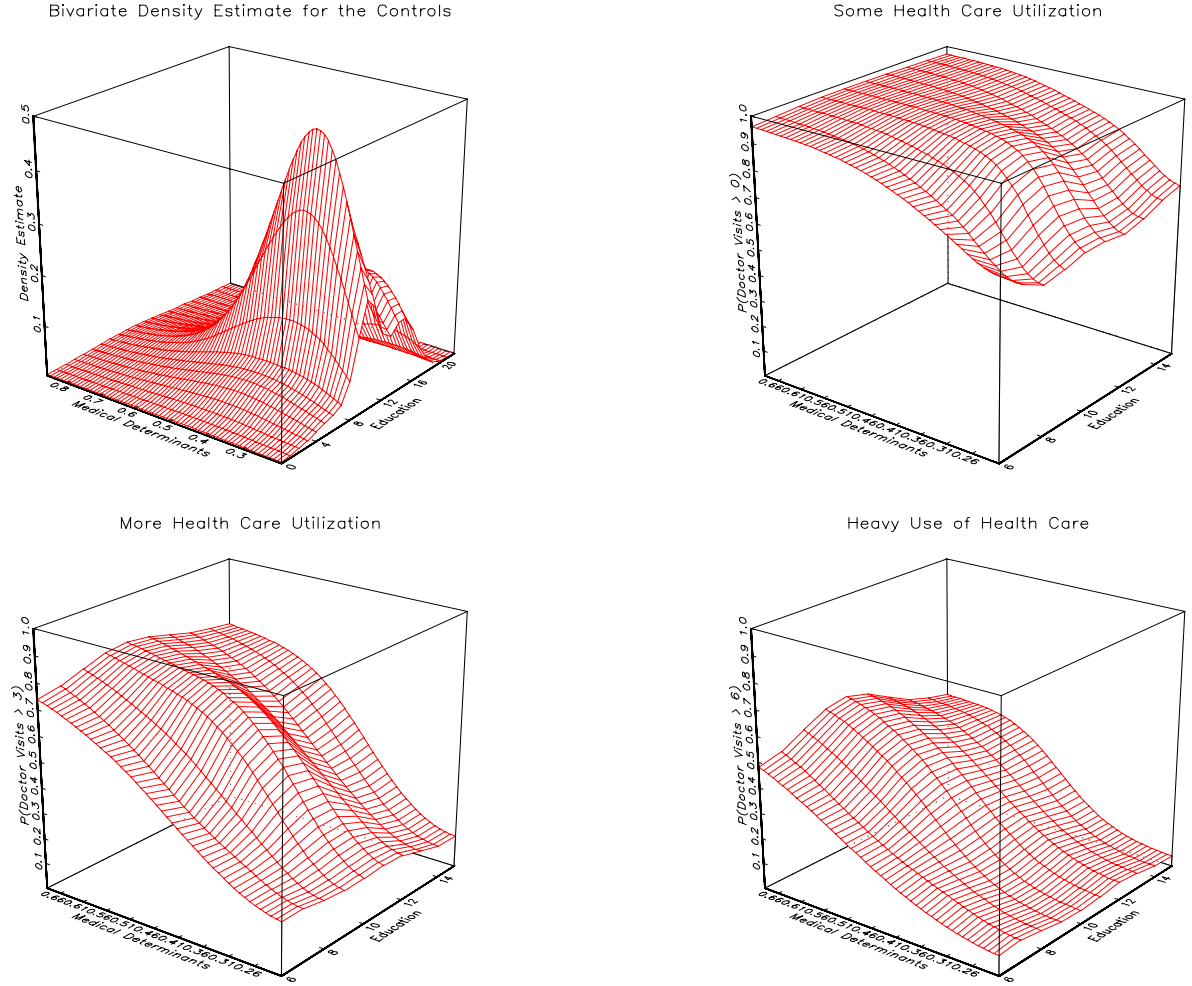
Figure 8: Health Care Utilization in Spain

A. Men
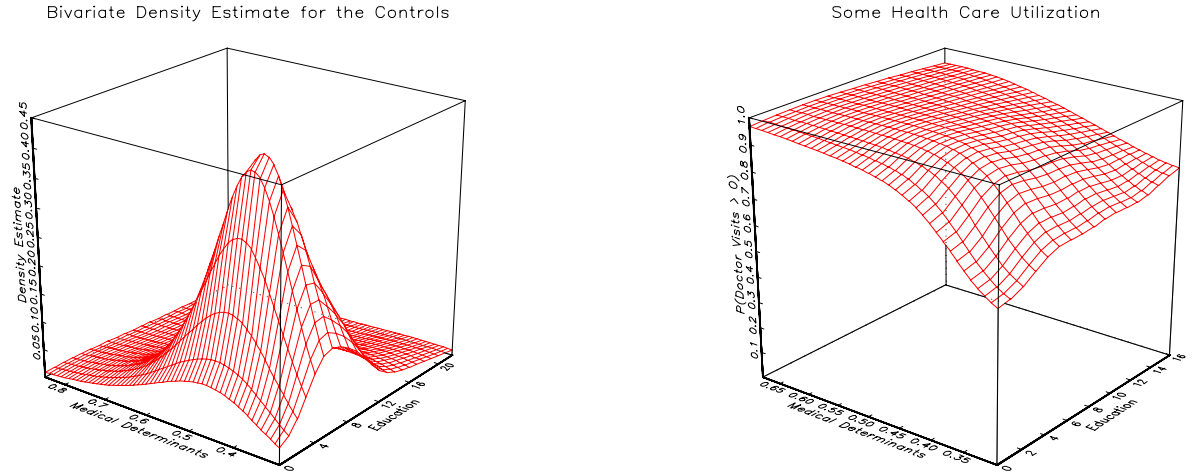

More Health Care Utilization
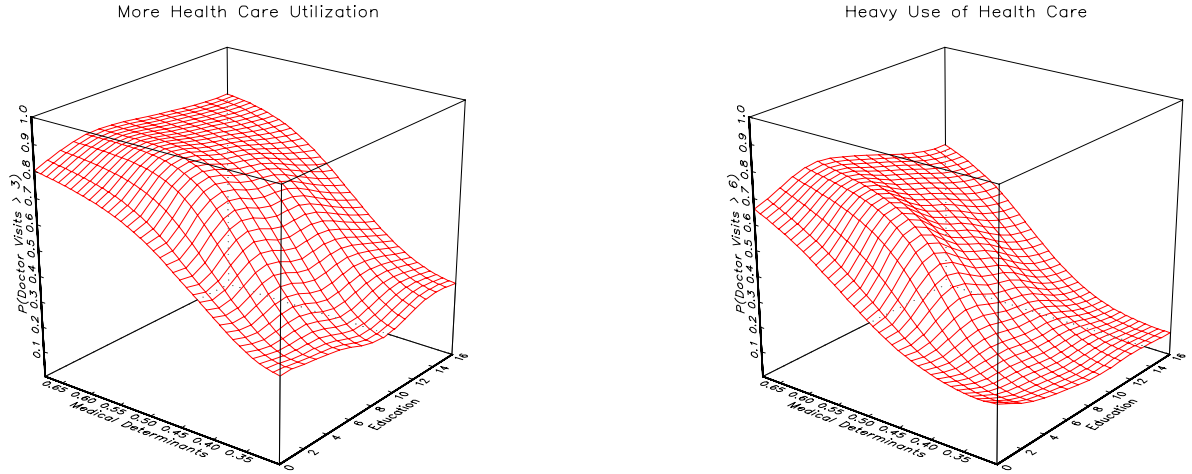

B. Women
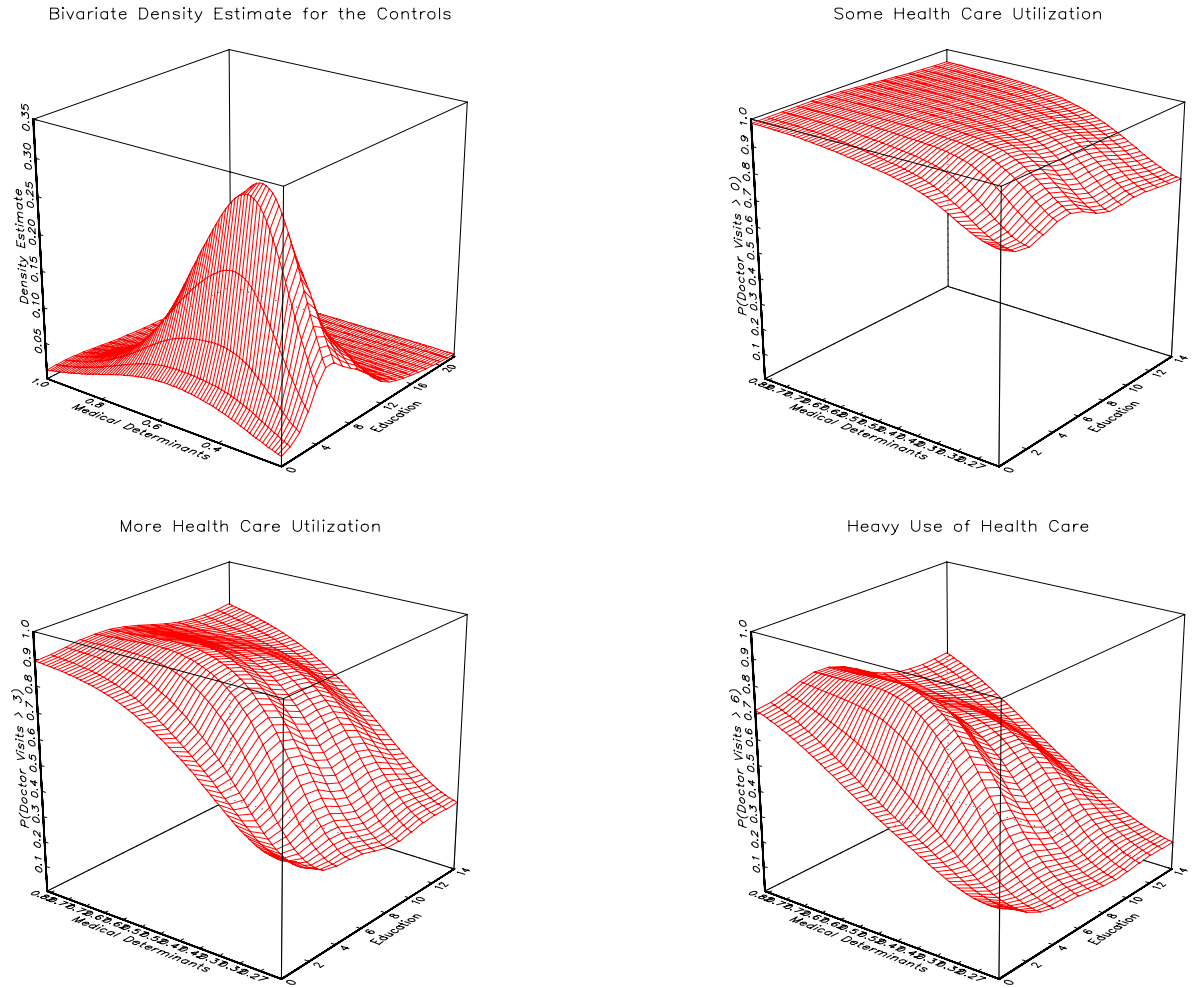
Figure 9: Health Care Utilization in Sweden

A. Men
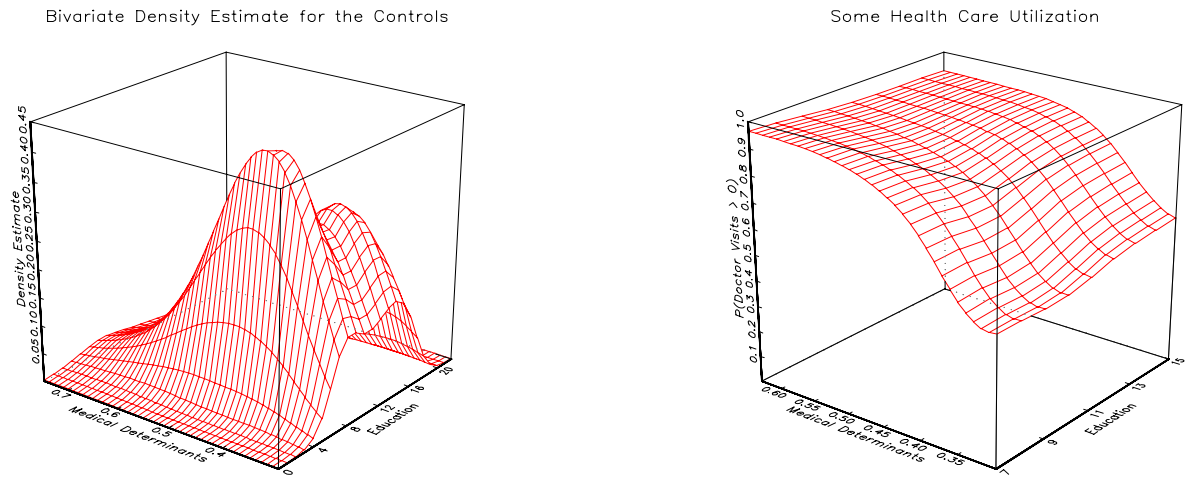

More Health Care Utilization
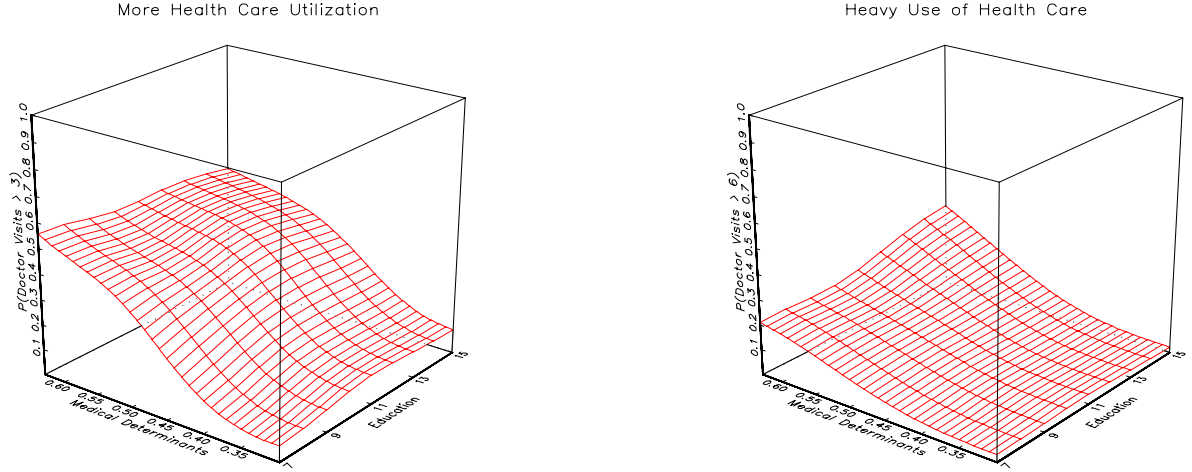

B. Women
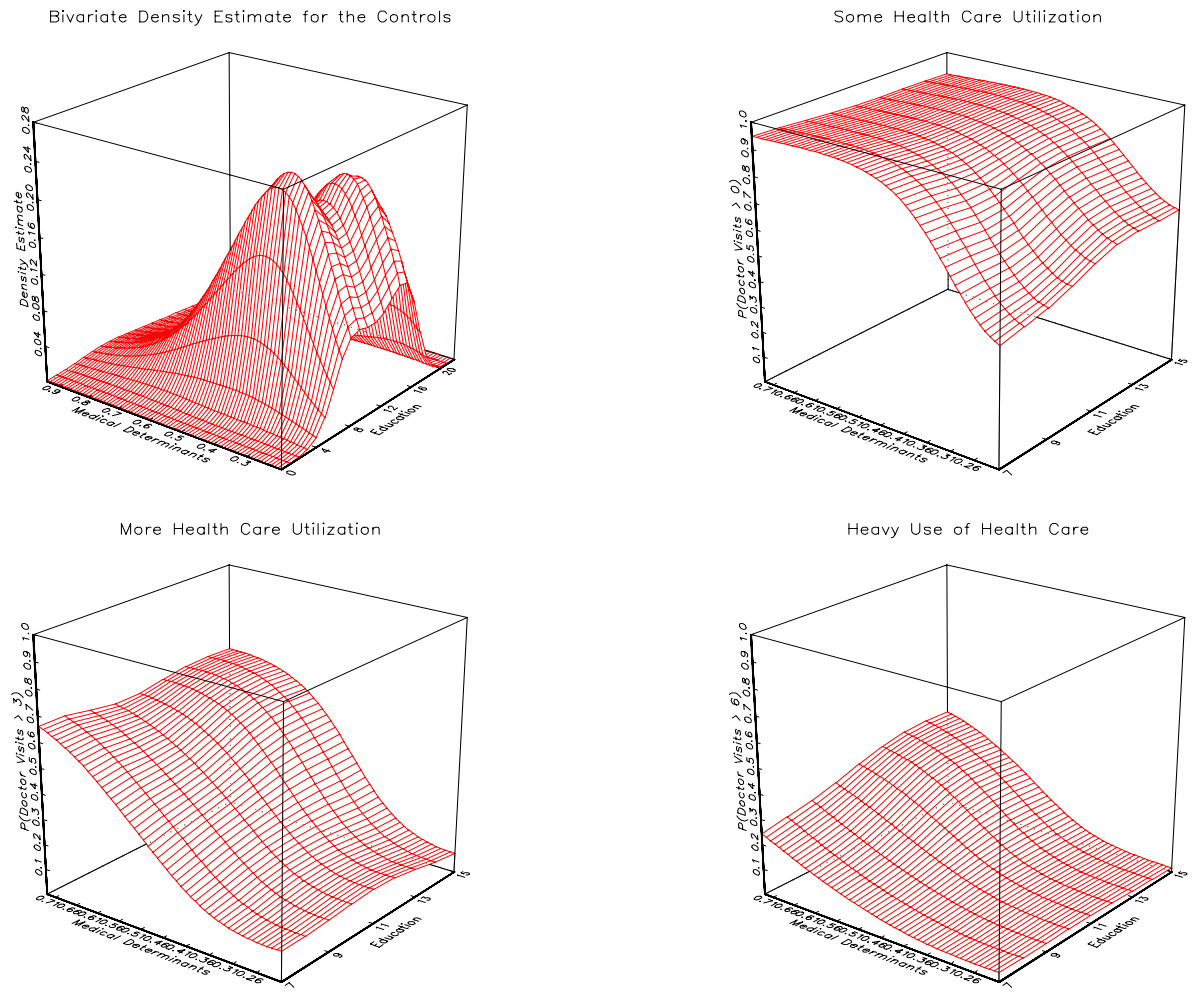
Figure 10: Health Care Utilization in Switzerland

A. Men
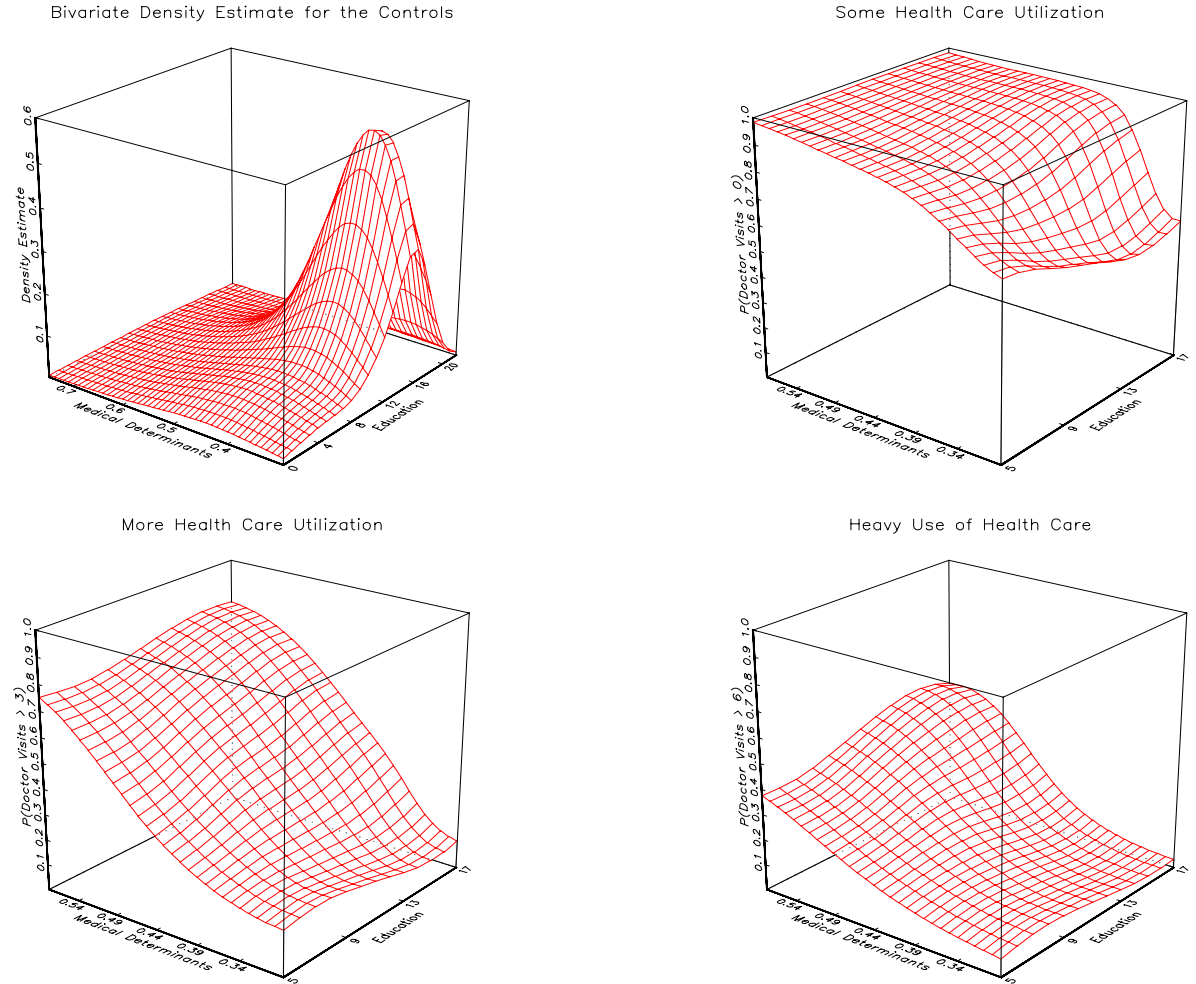

B. Women
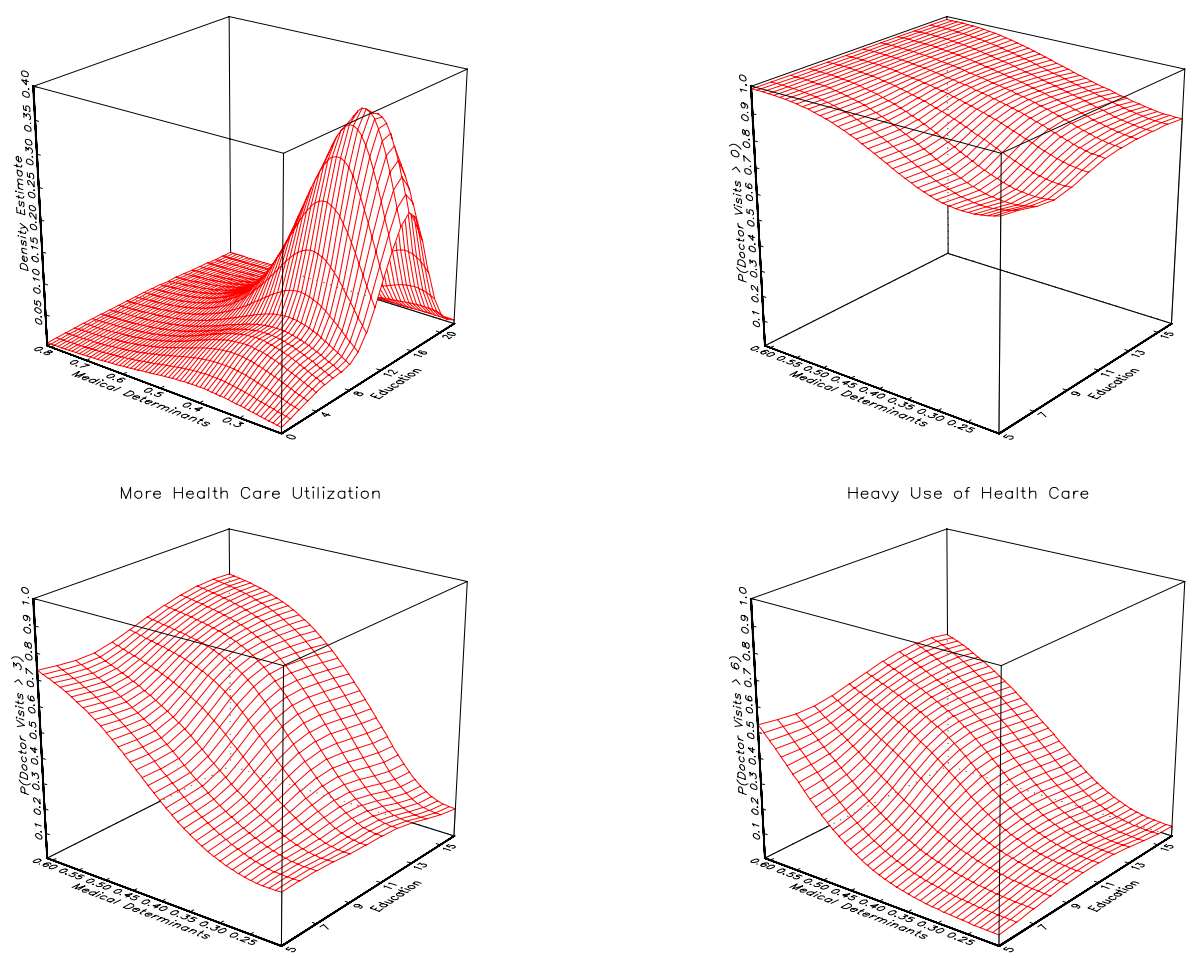
Figure 11: Partial Means for Selected Education Deciles
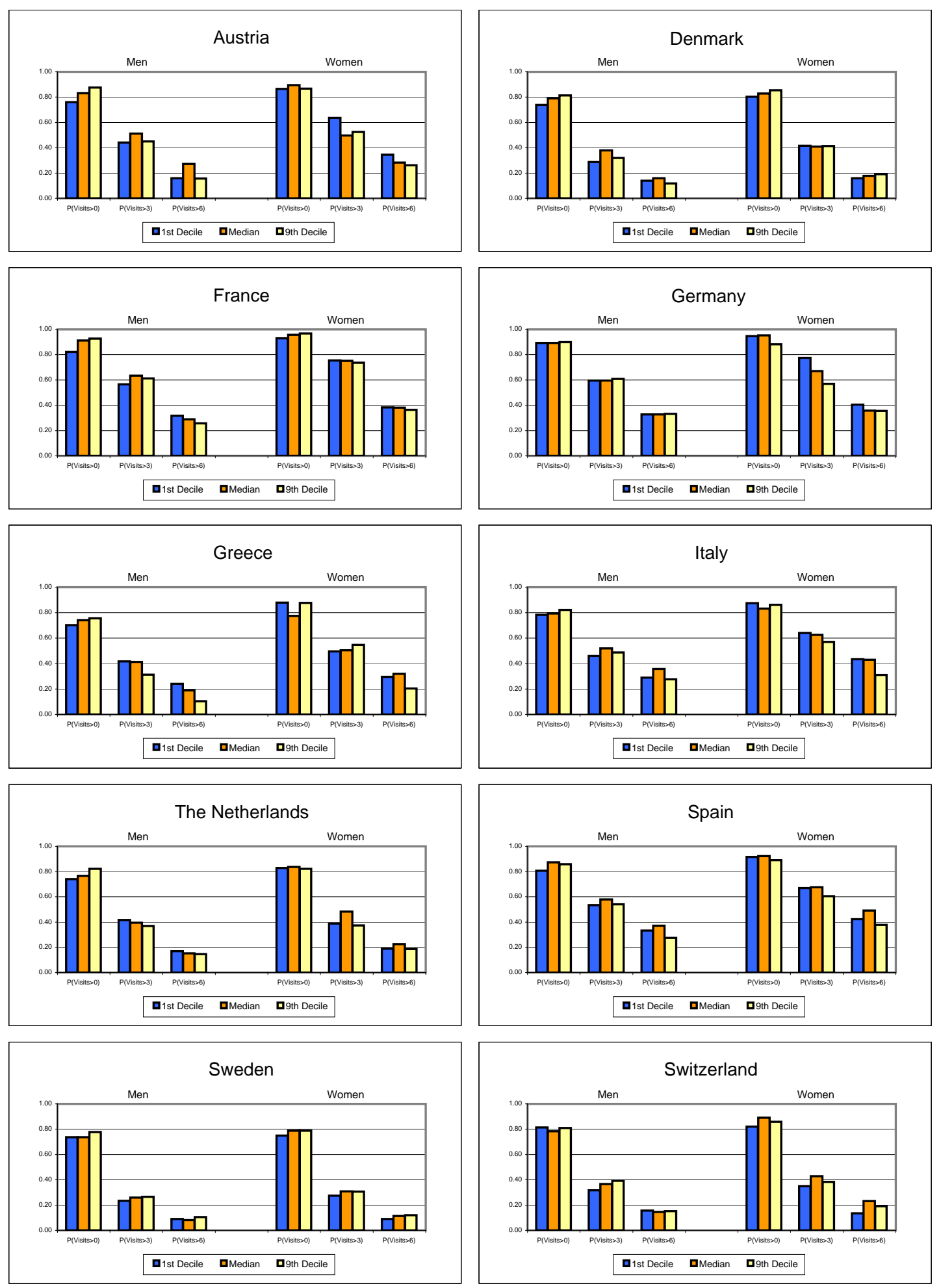
Figure 12: Partial Means for Selected Health Care Need Deciles
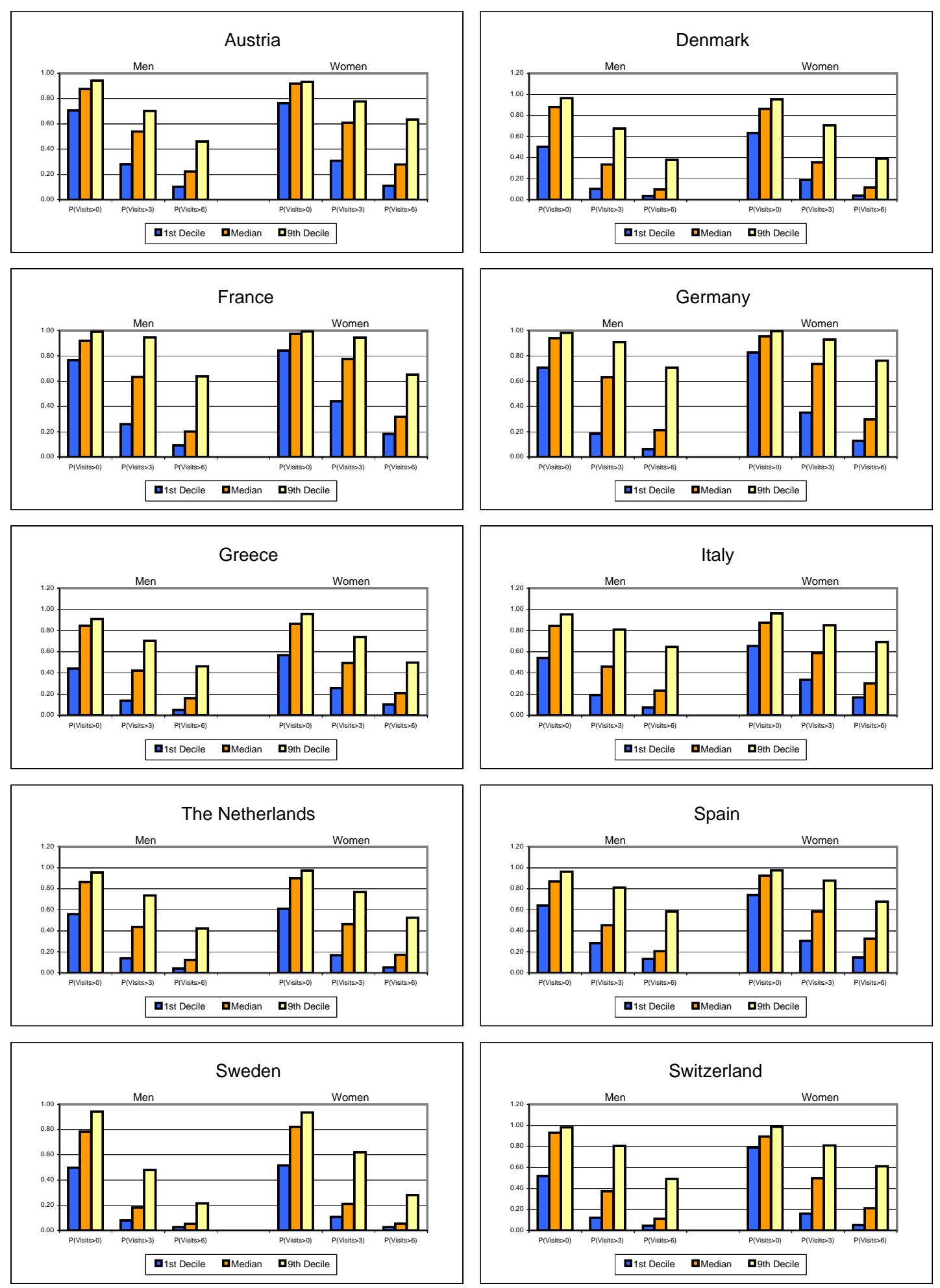


\section{Discussion Paper Series}

Mannheim Research Institute for the Economics of Aging Universität Mannheim

To order copies, please direct your request to the author of the title in question.

\begin{tabular}{|c|c|c|c|}
\hline Nr. & Autoren & Titel & Jahr \\
\hline $132-07$ & Axel Börsch-Supan & Rational Pension Reform & 07 \\
\hline $133-07$ & Axel Börsch-Supan & Über selbststabilisierende Rentensysteme & 07 \\
\hline $134-07$ & $\begin{array}{l}\text { Axel Börsch-Supan, } \\
\text { Hendrik Jürges }\end{array}$ & $\begin{array}{l}\text { Early Retirement, Social Security and Well- } \\
\text { Being in Germany }\end{array}$ & 07 \\
\hline $135-07$ & Axel Börsch-Supan & Work Disability, Health, and Incentive Effects & 07 \\
\hline $136-07$ & $\begin{array}{l}\text { Axel Börsch-Supan, } \\
\text { Anette Reil-Held, } \\
\text { Daniel Schunk }\end{array}$ & $\begin{array}{l}\text { The savings behaviour of German households: } \\
\text { First Experiences with state promoted private } \\
\text { pensions }\end{array}$ & 07 \\
\hline $137-07$ & $\begin{array}{l}\text { Hendrik Jürges, } \\
\text { Mauricio Avendano, } \\
\text { Johan Mackenbach }\end{array}$ & $\begin{array}{l}\text { How comparable are different measures of self- } \\
\text { rated health? Evidence from five European } \\
\text { countries }\end{array}$ & 07 \\
\hline $138-07$ & $\begin{array}{l}\text { Hendrik Jürges, } \\
\text { Kerstion Schneider }\end{array}$ & $\begin{array}{l}\text { What can go wrong will go wrong: Birthday } \\
\text { effects and early tracking in the German school } \\
\text { system }\end{array}$ & 07 \\
\hline $139-07$ & Hendrik Jürges & $\begin{array}{l}\text { Does ill health affect savings intentions? } \\
\text { Evidence from SHARE }\end{array}$ & 07 \\
\hline $140-07$ & Hendrik Jürges & $\begin{array}{l}\text { Health inequalities by education, income, and } \\
\text { wealth: a comparison of } 11 \text { European countries } \\
\text { and the US }\end{array}$ & 07 \\
\hline 141-07 & Hendrik Jürges & $\begin{array}{l}\text { Healthy minds in healthy bodies. An } \\
\text { international comparison of education-related } \\
\text { inequality in physical health among older adults }\end{array}$ & 07 \\
\hline $142-07$ & $\begin{array}{l}\text { Karsten Hank, } \\
\text { Stephanie Stuck }\end{array}$ & $\begin{array}{l}\text { Volunteer Work, Informal Help, and Care among } \\
\text { the 50+ in Europe: Further Evidence for 'Linked' } \\
\text { Productive Activities at Older Ages }\end{array}$ & 07 \\
\hline $143-07$ & Jürgen Maurer & $\begin{array}{l}\text { Assessing Horizontal Equity in Medication } \\
\text { Treatment Among Elderly Mexicans: Which } \\
\text { Socioeconomic Determinants Matter Most? }\end{array}$ & 07 \\
\hline $144-07$ & Jürgen Maurer & $\begin{array}{l}\text { Socioeconomic and Health Determinants of } \\
\text { Health Care Utilization Among Elderly } \\
\text { Europeans: A Semiparametric Assessment of } \\
\text { Equity, Intensity and Responsiveness for Ten } \\
\text { European Countries }\end{array}$ & 07 \\
\hline
\end{tabular}

